\title{
Performance Testing of Single Electrically Heated Fuel Pin Simulators for PWR LOCA Experiments
}

\author{
J. D. White
}

Prepared fo: the U.S. Nuclear Regulatory Commission Office of Nuclear Regulatory Research Under Interagency Agreements DOE 40-551-75 and 40-552-75 
ORNL/XLREG-3j

Dist. Category NRC-2

Contract No. W-?:nS-eng-26

Engineering Technology Division

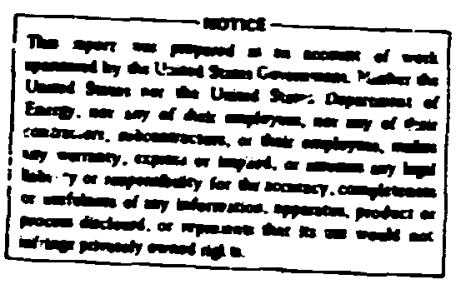

PERFORMANCE TESTING OF SINGLE FLECTRICALLY HEATED

FUEL PIN SIMULATORS FOR PIJP LOCA EXPERIMENTS

J. D. White

Manuscript Cot.pieted - Apríl 1i, 1978

Date Pun? isned - May 1978

Prepared for the

U.S. Nuclear Regulatory Commission

Office of Nuclear Regulatory Research

Under Interagency A.greements DCE 40-551-75 and 40-552-75

Prepared by the OAK RIDGE NATIONAL LABORATORY

Oak Ridge, Tennessee 37830

operated by

UNION CARBIDE CORPORATION

for the

DEPARTMENT OF ENERGY 


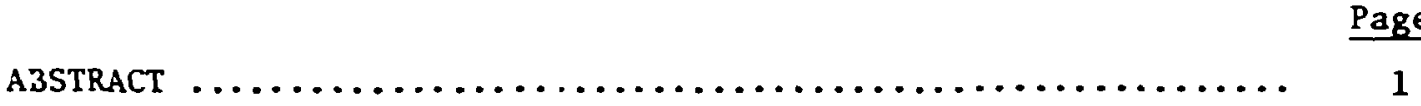

1. InTRODLCTION $\ldots \ldots \ldots \ldots \ldots \ldots \ldots \ldots \ldots \ldots \ldots \ldots \ldots \ldots \ldots \ldots \ldots \ldots$

1.1 NRC-Sponsored LOCA Research Programs .............. 2

1.2 ORNL PWR-BDHT Program ...................... 2

1.3 BDHT Task 1 - Testing of Fuel Pin Simulators ......... 4

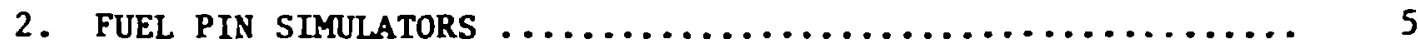

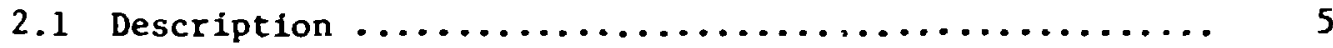

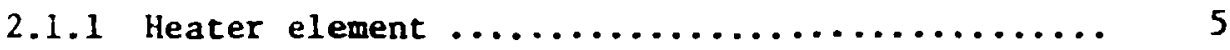

2.1.2 Thermocouples ....................... 9

2.2 Performance Requirements ..................... 14

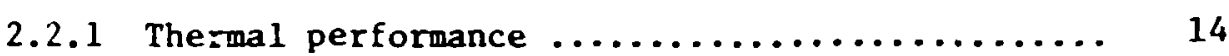

2.2.2 Electrical perfornanr $. \ldots \ldots \ldots \ldots \ldots \ldots \ldots \ldots . \ldots \ldots$

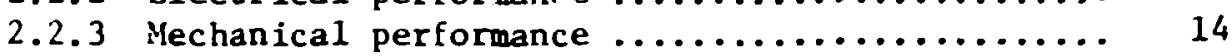

3. SINGLE-ROD TEST FACILITY DESCRIPTION $\ldots \ldots \ldots \ldots \ldots \ldots \ldots \ldots . \ldots \ldots$

3.1 Test Section Description ......................... 15

3.2 Steady-State Operation $\ldots \ldots \ldots \ldots \ldots \ldots \ldots \ldots \ldots \ldots . \ldots \ldots$

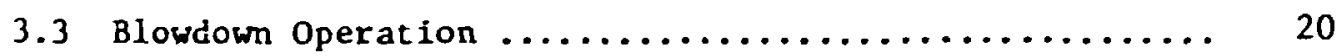

3.4 Data Acquisítion System .................... 21

4. PERFORMANCE TESTS OF FUEL PiN SIMLLATORS ............. 22

4.1 Summary of Experimental Testing Program ............ 22

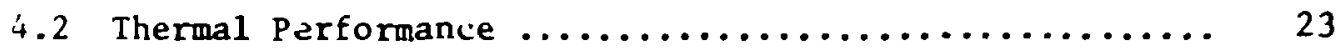

4.2.1 Reproducibility of thermocouple output ....... 23

4.2.2 Repeatability of radial $\Delta \mathrm{T} \ldots \ldots \ldots \ldots \ldots \ldots \ldots . . . . .33$

4.2.3 Beproducibility of time and location of CHF .... 38

4.2 .4 Time constants of sheath thermocouples ....... 44

4.3 Electrical Performance ................... 47

4.3 .1 Heater element resistance .............. 47

4.3.2 Insulation resistance of $I / g O$ and $B N \ldots \ldots . \ldots 49$

4.4 Mechanical Performance ..................... 50

4.4 .1 Retention of designed geometry ............ 50

4.4 .2 Integrity of heater surface $\ldots \ldots \ldots \ldots \ldots \ldots, \ldots . \ldots 52$

4.4 .3 Integrity of power connection ............ 52

4.4 .4 Adequacy of heater pressure seals .......... 53

4.4.5 Temperature limits for mechanical integrity .... 53

4.4.6 Degradation of contact betwoen swaged materials ......................... 55

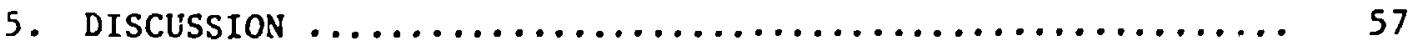

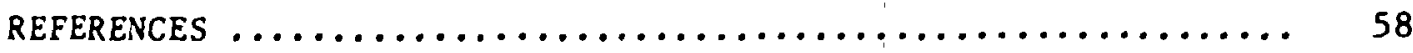




\title{
PERFORMANCE TESTING OF SINGLE ELECTRICALLY HEATED FUEL PIN SIMULATORS FOR PWR LOCA EXPERIMENTS
}

\author{
J. D. White
}

\section{ABSTRACT}

The ORNL PWR Blowdown Heat Transfer Program (PWR-BDHT) uses electrically heated fuel pin simulators in 49-rod bundles in steady-state and transient heat transfer experiments. The simulators have $3.66-m(12-f t)$ heated lengths and are $1.07 \mathrm{~cm}$ ( 0.422 in.) in diameter. In the transient experiments, a simulated large pipe break causes highly pressurized water to be depressurized and rapidly ejected from the primary system - a phenomenon known as blowdown. The hydraulic and thermal processes which occur in the bundle are similar to those predicted in a hypothetical loss-of-coolant accident (LOCA) in a PWR.

Prototypical fuel pin simulators zepresentative of the first two bundles have been cested singly for thermal, mechanical, and electrical performance in blowdown experiments in a single-rod lcop. Preliminary nondestructive tests were performed on all simulators prior to testing. As a result of the testing program, sjmulators for two 49-rod bundles sere bought. Representative samples of these two groups were tested in the same fashion as were the prototypes.

The electrical performance of each tested simulator was excellent. Measured parameters were resistance of the internal heater elemen: and resistance of the $B N$ and $M g O$ insulating materials. The mechanical performances of the simulators wero very good with respect to operability and survivability. A disappointing result, however, was that gaps appeared between the inner and outer parts of the dual-walled steel sheaths of bundle 1 prototypes and production heaters; raps also appeared in bundle 2 heaters, but the magnitudes seemed much smaller.

The thermal performances of the simulators were good with the exception of one aspect - repeatability of thermocouple output irot one experiment to the next. The gaps in heater sheaths grew as a function of temperature cycling with resultant increases in thermal resistances across the gaps. This effect diminished with the number of cycles. Other aspects of thermal performance were completely satisfactory: (1) reproducibility of time and location to transient CHF, (2) thermal time constants of thermocouples, (3) proper power profile, and (4) repeatability of heat flux profile. 


\section{INTRODUCTION}

\subsection{NRC-Sponsored LOCA Research Programs}

The U.S. Nuclear Regulatory Commission (NRC) sponsors several research programs associated with the hypothetical loss-of-coolant accident (LOCA) in a pressurized-water reactor (PWR). These programs study the hydraulic, thermal, mechanical, and chemical processes which might occur if the highly fressurized coolant were suddenly depressurized and rapidiy ejected from the primary system as a result of a large pipe break. The studies range from laboratory-scale experiments to small-scale nuclear plants. Experimental work and analytical model development pertinent to LOCA research are grouped into six major programs: Blowdown Heat Transfer, Reflood Heat Transfer, ECC Mixing and Bypass, LOCA Pump Behavior, LOCA Integral System Tests, and Aiternate ECCS Investigations. In the blowdown heat transfer area, the primary PWR experimental study is the ORNL PWR-BDHT program. ${ }^{1}$

\subsection{ORNL PWR-BDHT Program}

The ORNL Pressurized-Water Reactor Blowdown Heat Transfer (PWR-BDHT) Program provides data to determine the separate effects of power, system pressure, and break location on hydrodynamic behavior, time to critical heat $f l u x$, and transient heat transfer rates. A large nonnuclear experimental loop, $t$ ie Thermal-Hydraulic Test Facility (THTF), with a $7 \times 7$ array of 3.66-m-long ( $12-f t)$ electrically heated rods is used $t$ ) generate the data.

Specific objectives of the ORNL-PWR-BDHT Separate-Effects Program are (1) to concurrently determine, for a wide range of parameters, pre-CHF (cricical heat flux) hear. fluxes, $\Delta T$, heat transfer coefficients, and local fluid properties; time to CHF; and post-CHF heat fluxes, $\Delta \mathrm{T}$, heat transfer coefficients, and local fluid properties; and (2) to test the ability of existing codes, such as RELAP, to predict the behavior of the single-rod and 49-rod loops under blowdown conitions. 
The parameters to be studied include:

1. single- and double-ended coolant line breaks of varying area ratio,

2. depressurization rates varyi.'g from "fast" to "slow,"

3. different combinations of sys em power and pressure to obtain different values of departure from lucleate boiling ratio (DNBR),

4. a range of power cutoff delays,

5. a range of power decay rates,

6. a range of fower to system volume ratios.

Secondary objectives are (1) to obtain CHF data under steady-state conditions over a range of coolant pressures, inlet and exit subcooling, and inlet flow rate appropriate to PWR interests; (2) to evaluate the thermal-hydraulic behavior of the test loops during simulated operational upsets that include variations in local power, system pressize, or coolant flow using the anticipated transient without scram (ATWS) as described in WASH$1270^{2}$ as a guide; and (3) to determine the effect of different spacer grids and power distribution profiles on both transient and steady-state CHF.

The program objectives are accomplished through seven interrelated tasks, ${ }^{3}$ as shown in Fig. 1.1. These tasks are:

1. Forced-Convection Test Faciity (FCTF) operations,

2. analysis,

3. THTF operations,

4. two-phase flow instrumentation,

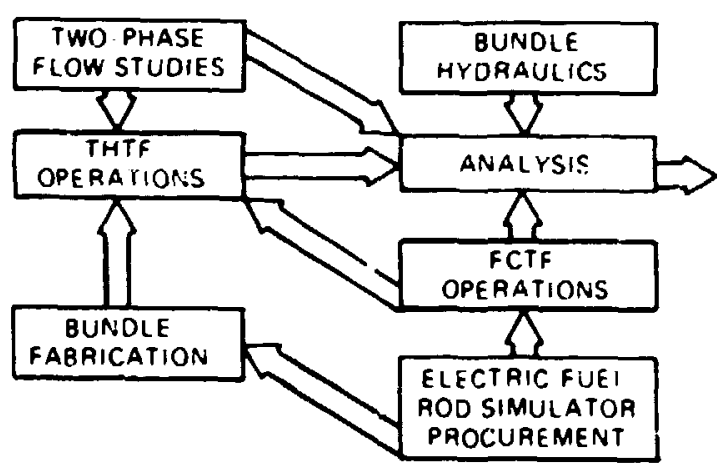

Fig. 1.1. The BDHT program is divided into seven interrelated tasks. 
5. bundle fabrication,

6. fuel pin simulator procurement,

7. bundle hydraulics.

\subsection{BDHT Task 1 - Testing of Fuel Pin Simulators}

The primary objective of task 1 (FCTF operations) is the evaluation of the thermal, electrical, and mechanical performances of electrical fuel pin simulators. This testing is necessary to establish the suitability of different prototypical sinulator designs for use in the THTF 49-rod bundle. If a specific prototypical design proves adequate, enough fuel pin simulators of that design are purchased to build a bundle and to provide a batch of simulators for further testing in the FCTF. This further testing is necessary to ensure that the simulators produced in the production line manner at the vendor plant will perform as well as the prototypes tested previously. Testing of these simulators also provides data to be used by the analysis task (task 2) in preparation of analytical models before THTF data become available.

This report describes the various cests used in the evaluation of simulator performance. The fuel pin simulator used in a typicai THTF bundle is described, its performance requirements are discussed, and a brief description of the single-rod test loop is presented. Results of simulator performance tests for THTF bundles 1 and 2 units are also given. 


\section{FUEL PIN SIMULATORS}

\subsection{Description}

The indirect heater rod used in the THTF test bundle is a $1.07-\mathrm{cm}-O D$ (0.422-in.) rod with a 3.66-m-long (12-ft) stepped, chopped-cosine profile and an overill length of $6.1 \mathrm{~m}(20 \mathrm{ft})$ (Fig. 2.1). The heater rod is double-ended, with the sheath and ground-lead extension welded together at the lower end and the power 1 sad-in insulateci from the sheath at the upper end. Heat generated by the tubular heating element on the interior of the heater rod is conducted through boron nitride insulation to the dual-walled outside sheath of the rod. Thermocouples are located on the center line of the rod as well as in grooves in the inner layer of the dual-walled outer sheath.

\section{1 .1 Heater element}

The heacer element conststs of a series of oversleeves swaged over a central heater tube to provide a series of different power level heatgeneration zones. The center $0.91 \mathrm{~m}$ ( $36 \mathrm{in.}$ ) consists of only the basic Inconel 600 heater tube, thus giving the highest resistance to provide a maximum heat-generation rate of $6.10 \mathrm{~kW} / \mathrm{m}$ when the current is $2600 \mathrm{~A}$.

Successive oversleeves of Inconel 600 or cupronickel of appropriate wall thicknesses and lengths are swaged over the appropriate length of the heater element. Each of these oversleeves extelits to the end of the heater element, thus eliminating any butt joints within the heater element itself. As successive sleeves are added between thie center zone and the ends, the resistance - and thus the heat-generation rate - of that particular zon: decreases so that the series of step changes bracket the desired choppedcosine power profile as shown in Fig. 2.2. The lengths of the steps for different power levels were chosen to match the integrated power profile of the chopped-cosine power profile (Fig. 2.3). Nominal heated zone lengths, power ratios, and local powers for THT bundle 1 and bundle 2 heater rods are given in Table 2.1 . 
$4 \%$ WELDING CABLE AND COPPER CONNECTOR LUG TO CONDLCT 600 AMPS PER ROD
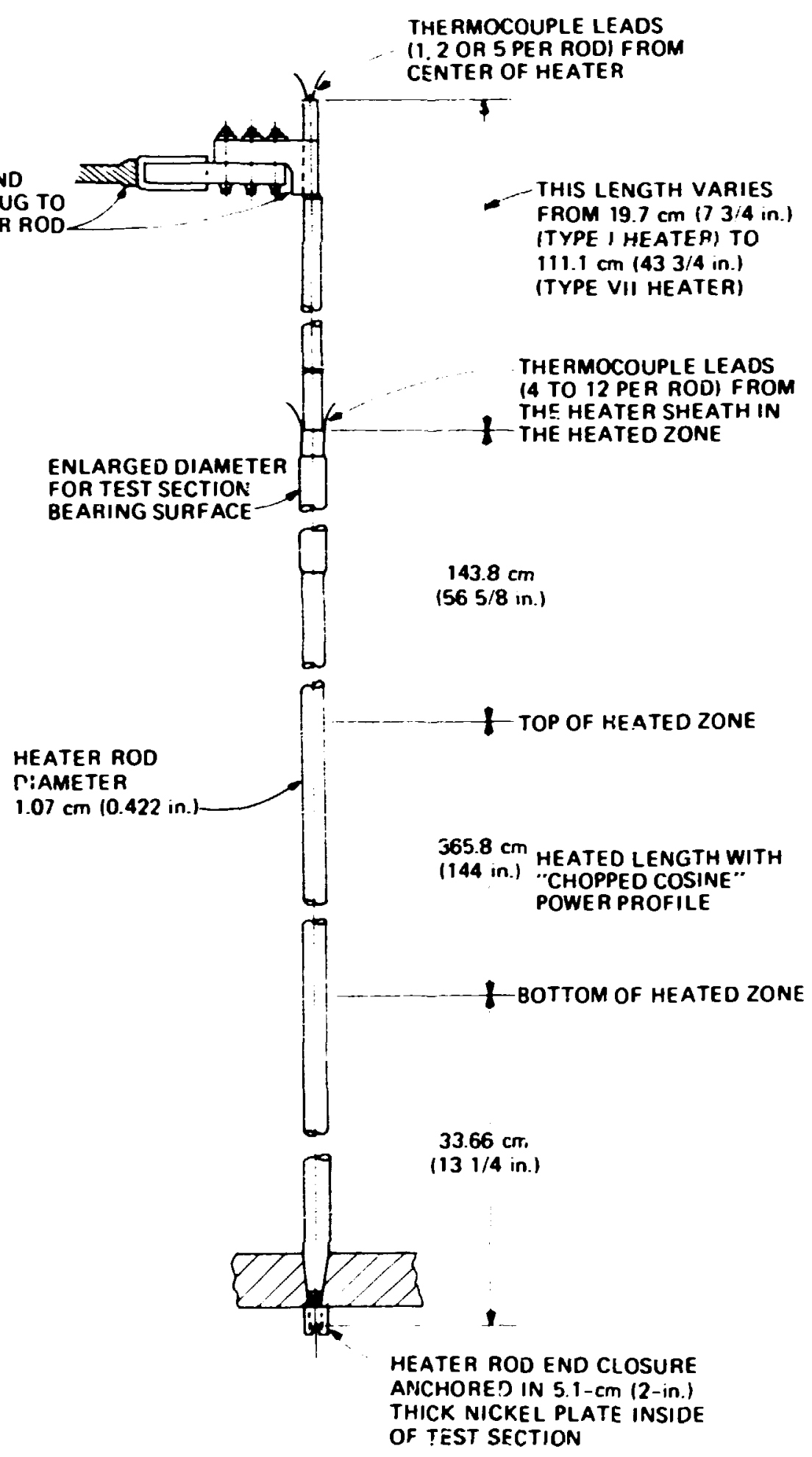

Fig. 2.1. Indirect heater rod assembly. 
AV: corro is: :50:A

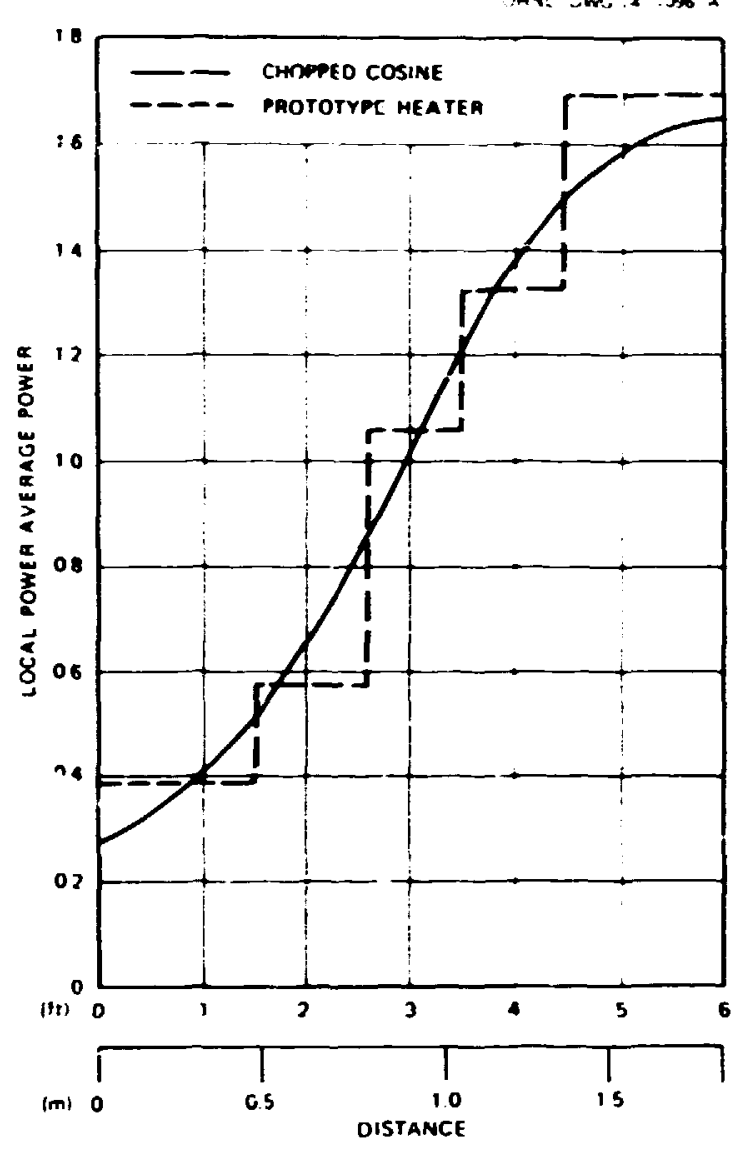

Fig. 2.2. Power profile of BDHT fuel pin si.nulator.

Table 2.1. Nominal power profile for $\mathrm{BDHT}$ fuel pin simulator with average power of $39.4 \mathrm{~kW} / \mathrm{m}(12 \mathrm{~kW} / \mathrm{ft})$

\begin{tabular}{lll}
\hline $\begin{array}{c}\text { Length of heater zone } \\
\text { beginning to end } \\
\text { [cm (in.)] }\end{array}$ & $\begin{array}{c}\text { Power ratio, } \\
\text { local/average }\end{array}$ & $\begin{array}{c}\text { Local power rate } \\
\text { [kW/m (kW/ft)] }\end{array}$ \\
\hline $\begin{array}{c}0-45.7(0-18) \\
45.7-80.0(18-31.5)\end{array}$ & 0.422 & $16.60(5.06)$ \\
$80.0-106.7(31.5-42)$ & 0.597 & $23.49(7.16)$ \\
$106.7-137.2(42-54)$ & 1.065 & $41.93(12.78)$ \\
$137.2-228.6(54-90)$ & 1.285 & $50.59(15.42)$ \\
$228.6-259.0(90-102)$ & 1.67 & $65.62(20.0)$ \\
$259.0-285.8(102-112.5)$ & 1.285 & $50.59(15.42)$ \\
$285.8-320.0(112.5-126)$ & 1.065 & $41.93(12.78)$ \\
$320.0-365.8(126-144)$ & 0.597 & $23.49(7.16)$ \\
\hline
\end{tabular}




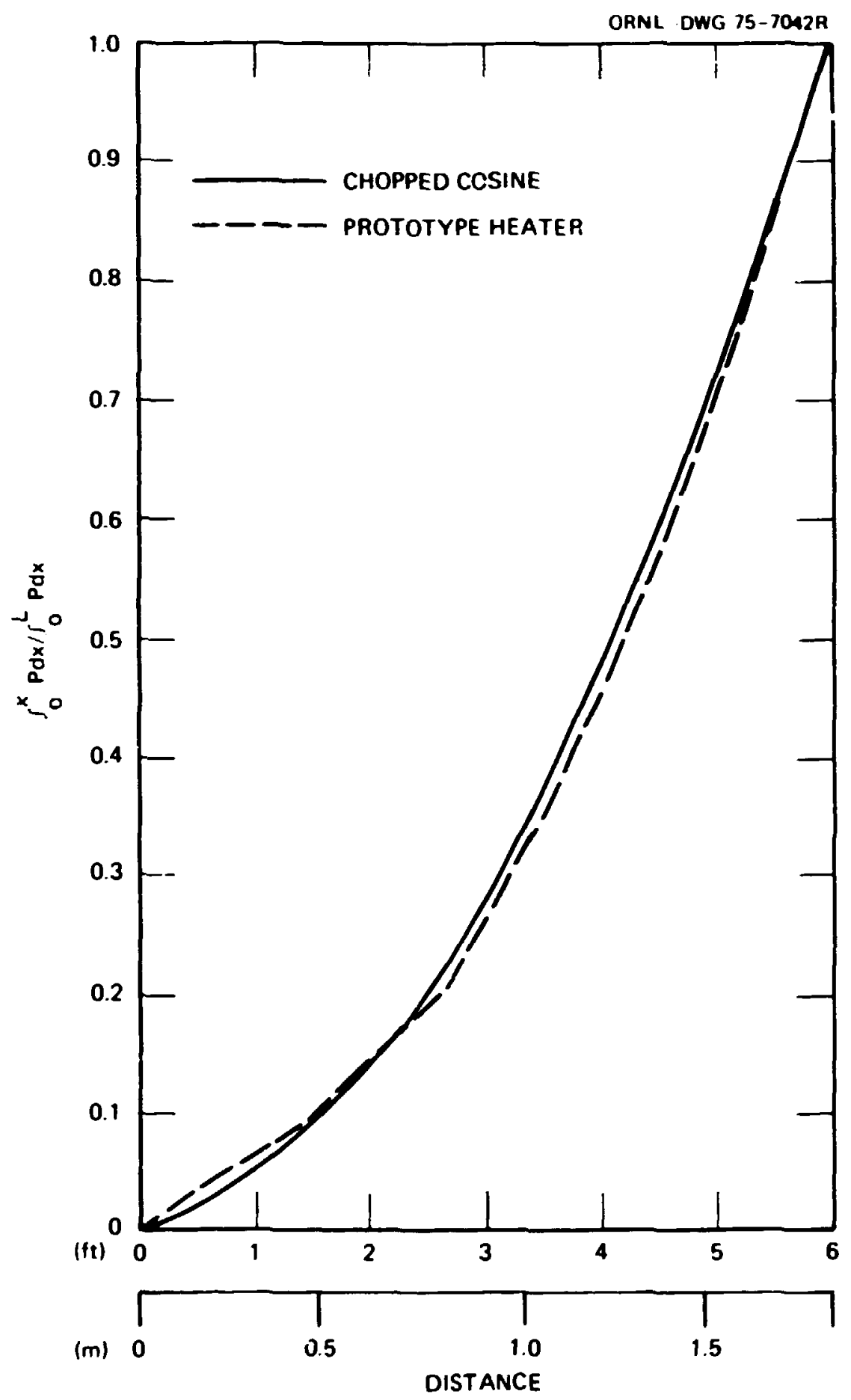

Fig. 2.3. Designed fuel pin simulator integrated power profile conpared to integrated chopped cosine power profile. 


\subsubsection{Thermocouples}

Heaters for bundles 1 and 2 were purchased with four different totals for chermocouples per rod and five different nominal locations for thermocouples. These are summarized in Table 2.2. Thermocouples both on the rod center and in the rod sheath are 0.5-mm-CD (C.020-in.) sheathed Chromel-Alumel thermocouples with $\mathrm{YgO}$ insulation between the thermocouple and the stainless steel thermocouple sheath. The central rod thermocouple sheaths are insulated from the Inconel heater element by Mgo. The sheatin thermocouples are located, two to a groove, in axial grooves machined in the 0.76-mm-thick (0.030-in.) inner sheath. After the tip of a thermocouple sheath is spot-welded at the proper location in the groove, stainless steel filler rod is added to the remainder of the axial length of the groove and the outer sheach is swaged over the inner sheath (Fig. 2.4). The outer sheath thickness is 0.25 mu ( $0.010 \mathrm{in.)}$ for bundle 1 heaters and $0.38 \mathrm{~mm}(0.015 \mathrm{in.})$ for bundle 2. Cross sections of a heater rod at different axial levels are shown in Fig. 2.5. A final swaging process reduces heater outside diameters to $1.07 \mathrm{~cm}(0.422 \mathrm{in.})$ for both bundles 1 and 2 .

The junctions of the center and sheath thermocuuples are near the ends of heated zones for bundle 1 heaters (Fig. 2.6). Burdle 2 heaters have thermocouple junctions near the middles of the heated zones (Fig. 2.7).

Table 2.2. Summary of fuel pin simulator designation and cotal number of thermocouples

\begin{tabular}{llrr}
\hline $\begin{array}{c}\text { Simulator } \\
\text { type }\end{array}$ & \multicolumn{3}{c}{ Number of thermocouples } \\
\cline { 2 - 4 } & Center & Sheath & Total \\
H & 5 & 10 & 15 \\
$\mathrm{~J}$ & 5 & 12 & 17 \\
$\mathrm{~K}$ & 5 & 12 & 17 \\
M & 2 & 10 & 12 \\
$\mathrm{P}$ & 1 & 4 & 5 \\
\hline
\end{tabular}




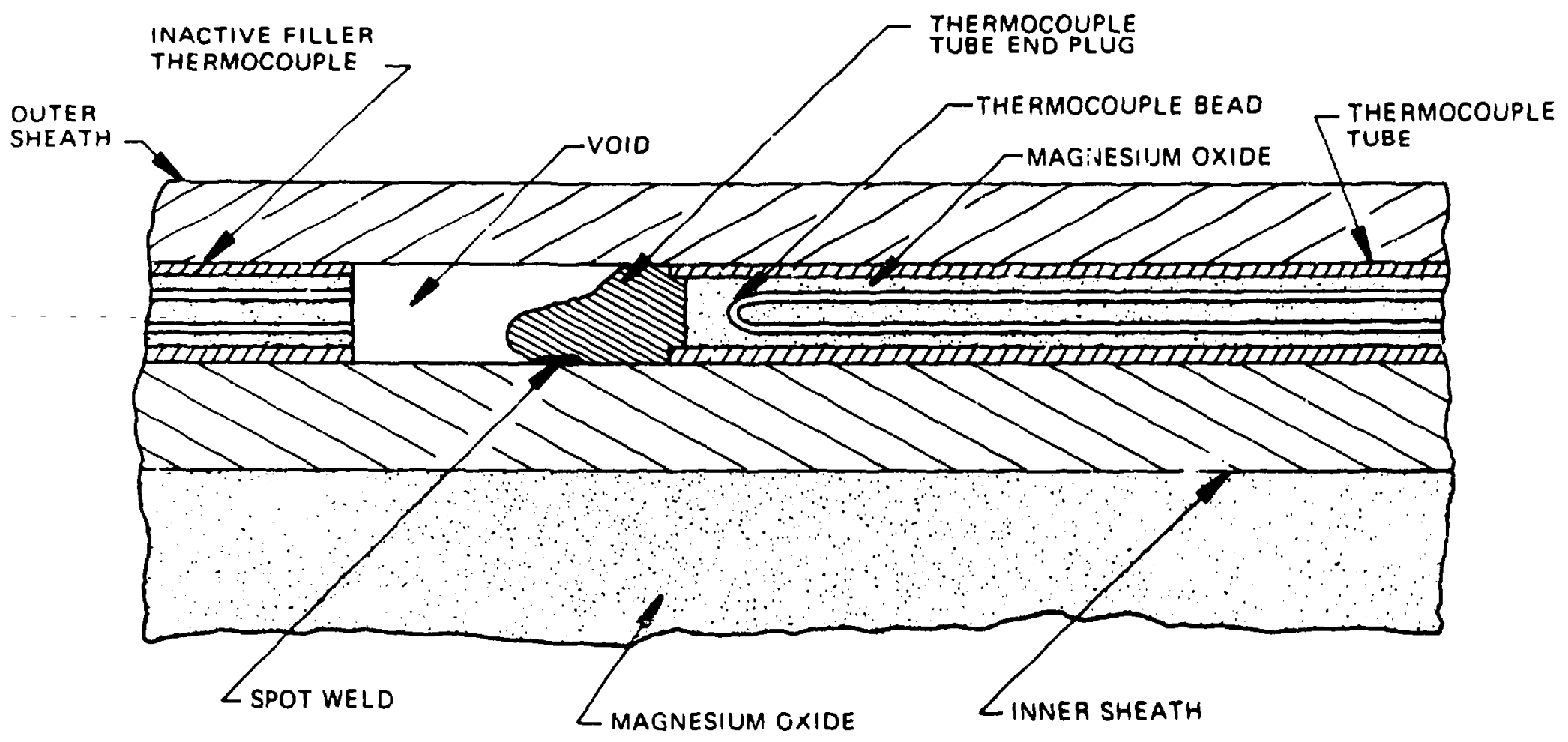

Fig. 2.4. Typical steath thermocouple function configuration. 


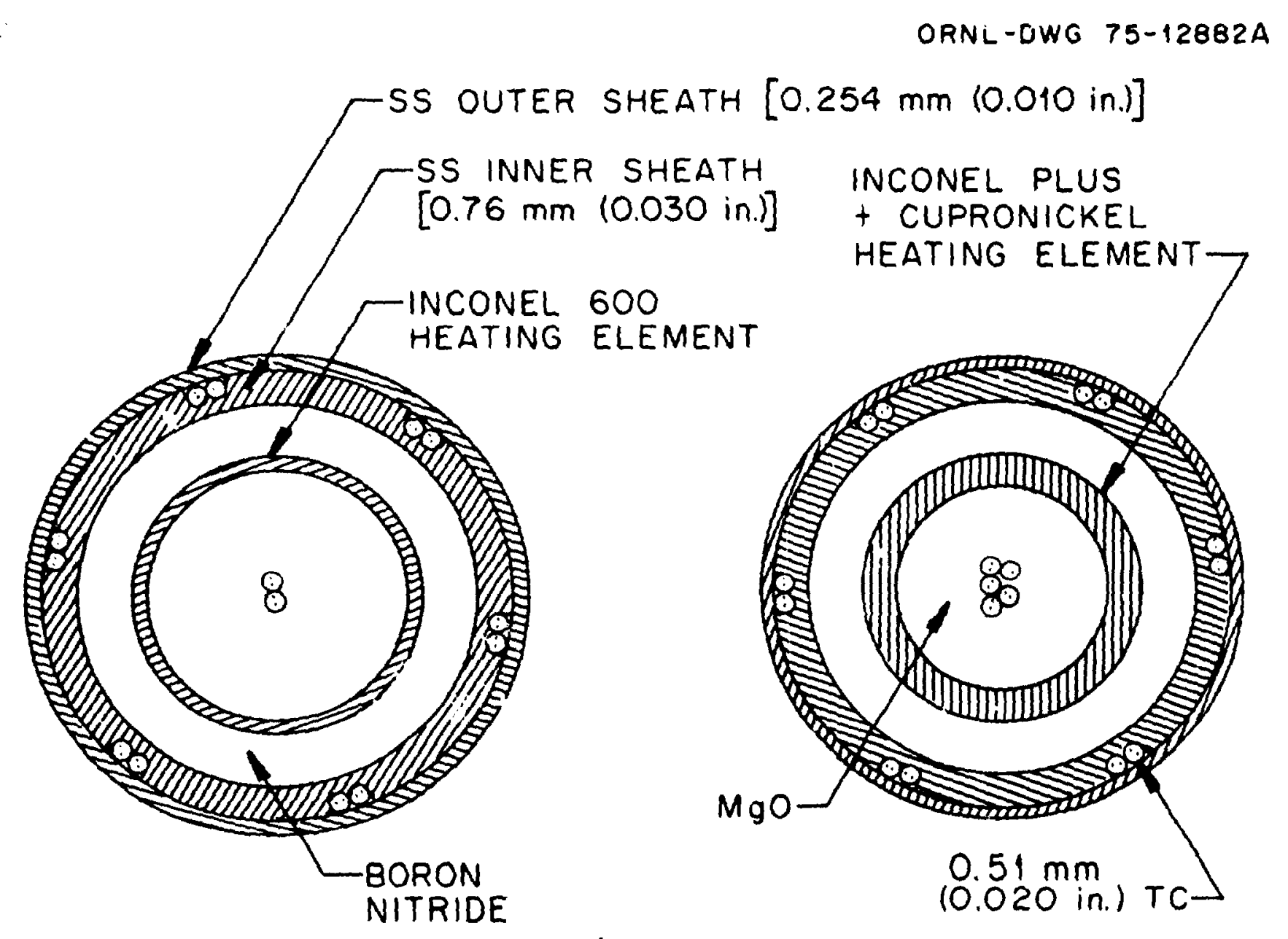

Fig. 2.5. Fuel pin simulator cross section. 


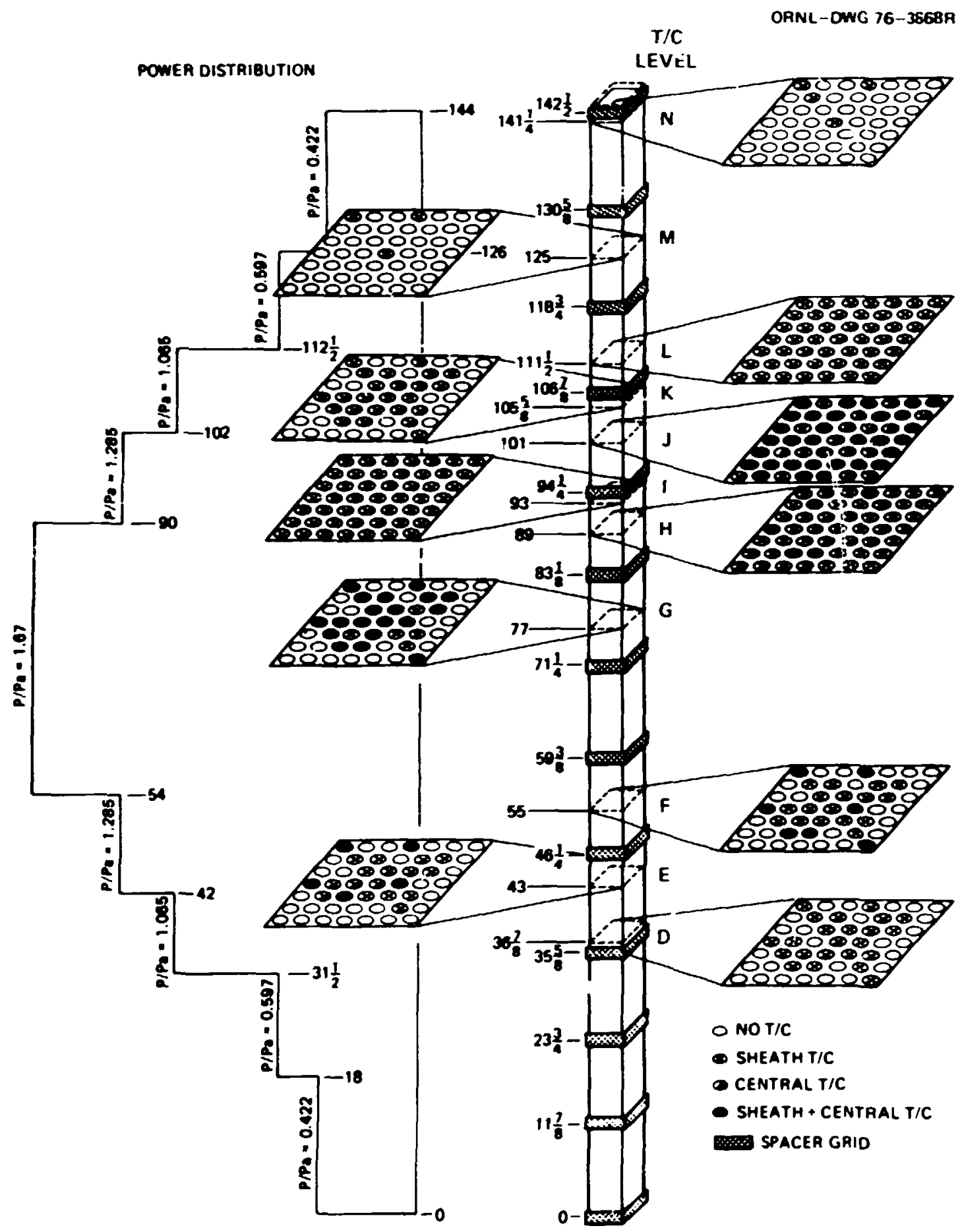

Fig. 2.6. Speciffed locations of fuel pin simulator thermocouples for THTF bundle 1 . (Dimensions in inches; $1 \mathrm{~m}=39.37 \mathrm{in.)}$ 


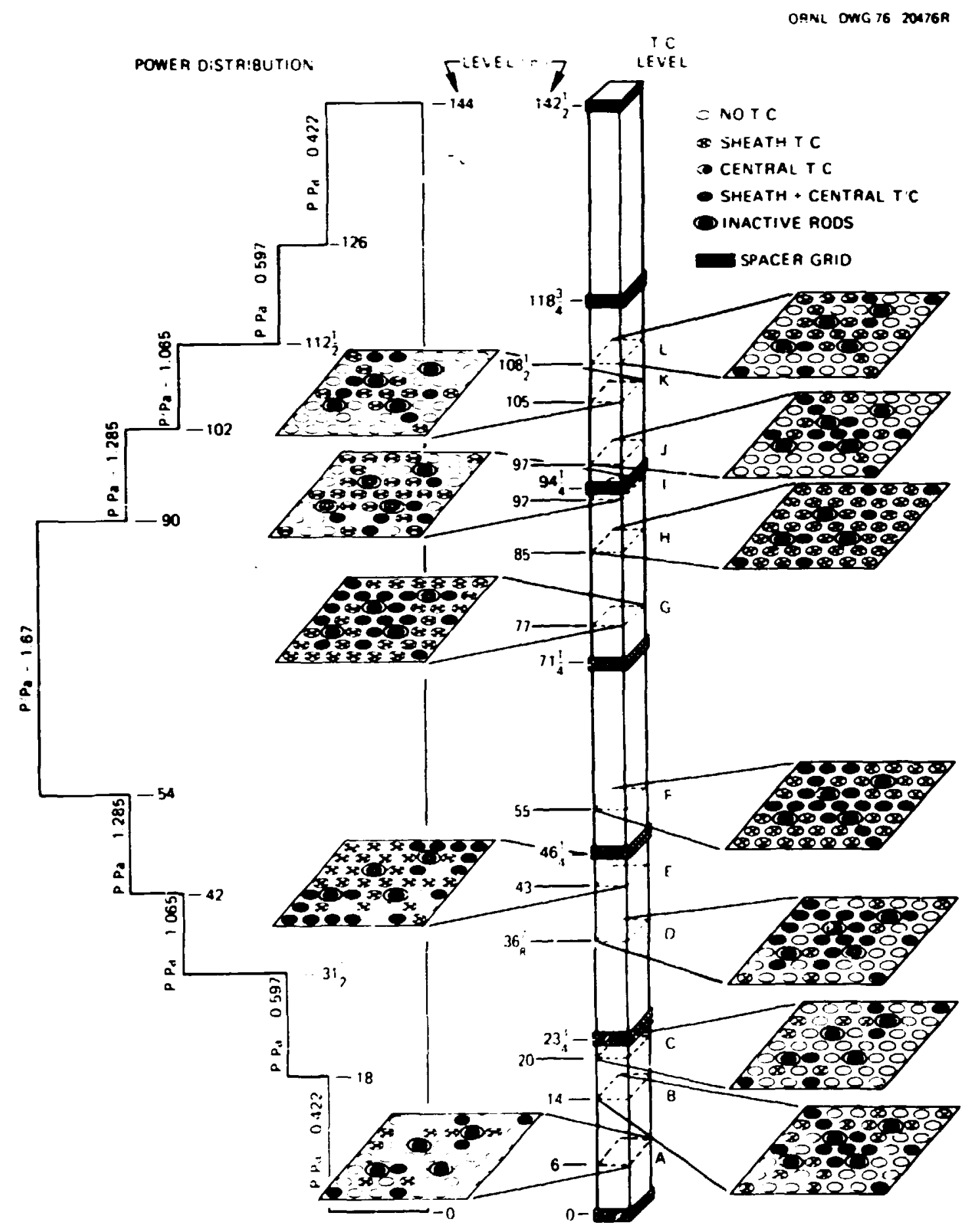

Fig. 2.7. Specified locations of fuel pin simulator thermocouples for THTF bundle 2. (Dimensions in inches; $1 \mathrm{~m}=39.37 \mathrm{in.)}$ 


\subsection{Performance Requirements}

\subsubsection{Therwal performance}

The power-generating section of the heater must be at least $3.66 \mathrm{~m}$ long (12 ft) and capable of operating at a total power of $150 \mathrm{~kW}$. The shape of power profile should approsimate that of a chopped cosine with a peak-to-average power ratio of at least 1.65 . The steady-state ridial temperature profile should remain constant from run to run at identical conditions or must vary in a calculable manner. Thermometry of the heater must detect the time and location of a surface heat transier crisis (CHF).

\subsubsection{Electrical performance}

The heater element resistance must be stable with operating temperature, and sheath thermocouples must remain electrically insulated from the heater sheath. Leakagi of current from the heating element to the internal thermocouples and to the heater sheath should be minimal. No areas of locally high resistance (hot spots) should develop in the heater, and the thermosuuples should respond reproducibly.

\subsubsection{Mechanical performance}

The designed mechanical geometry of the heater should not change with steady-state or transient operation, and the integrity of brazed and welded power connections should not deteriorate. The heater pressure seals must hold in steam environments where the heater is expanding and contracting. The heater surcace must not be violated. No degradation of contact between swaged materlals should result from the blowdown testing. 


\section{SINGLE-ROD TEST FACILITY DESCRIPTION}

The Forced Convection Test Facility (FCTF) provides an environment for performance testing of electrically heated fuel pin simulators in steady-state and transient (blowdown) mo :as. The facility consists of a high-pressure closed loop and a low-pressure energy absorption tank (Fig. 3.1). A buffer pressure zone confined by a pair of rupture disks isolates the high-pressure system rom the low-pressure system. The high-pressure system $\left(15.5 \mathrm{mN} / \mathrm{m}^{2}\right.$ r $\left.2250 \mathrm{psia}\right)$ contains the test section, a canned rotor pump, a pressurizer, a heat exchanger, and a bypass line. The low-pressure system is a large tank with cold water to absorb the energy of the blowdown effluent; a $6.3-\mathrm{dm}^{3} / \mathrm{sec}(100-\mathrm{gpm})$ pump circulates cold water to condense the steam. A water injection pump supplies 12.6 $\mathrm{cm}^{3} / \mathrm{sec}(0.2 \mathrm{gpm})$ of room-temperature water to quench the fuel pin simulator after the blowdown.

\subsection{Test Section Description}

A cross-secticnal view of the current test section is shown in Fig. 3.2. The test section housing is $5.08-\mathrm{cm}\left(2-\mathrm{in}_{\text {. }}\right)$ sched-80 stainless steel pipe. The annular area between the housing and the $2.54-\mathrm{cm}(1-\mathrm{in}$. sched-80 stainless steel core barrel is a downcomer. At steady state, water flows down the downcomer and up the annulus between the heater rod and the core barrel. Spacer grid sections spaced $0.61 \mathrm{~m}(2 \mathrm{ft}$ ) apart are tack-welded to the heater rod. These grids prevent the heater surface from touching the wall of the core barrel.

The bottom of the test section contains a large nickel electrode into which fits the tapered ground plug of the fuel pin simulator (Fig. 3.3) in the same manner as in the THTF. At the top of the test section, an 0-ring seal assembly (Fig. 3.4), similar to that in the THTF, provides a pressure seal with elastomer $0-r i n g s$ held against the fuel pin sinulator bearing surface. During operation, the heater slides up and down through the 0-rings because of thermal expansion relative to that of the test section housing. 


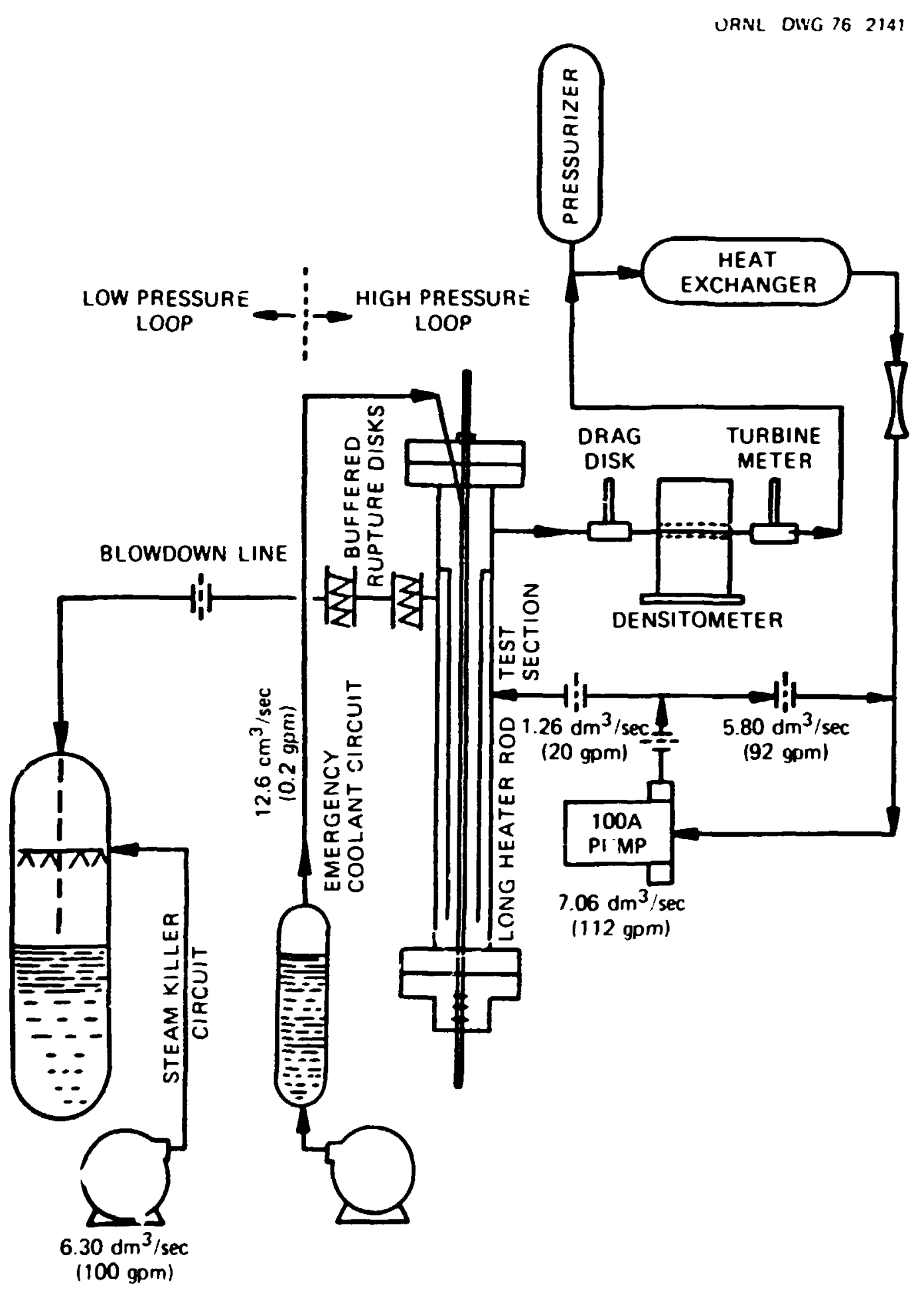

Fig. 3.1. Forced convection test facility (FCTF). 


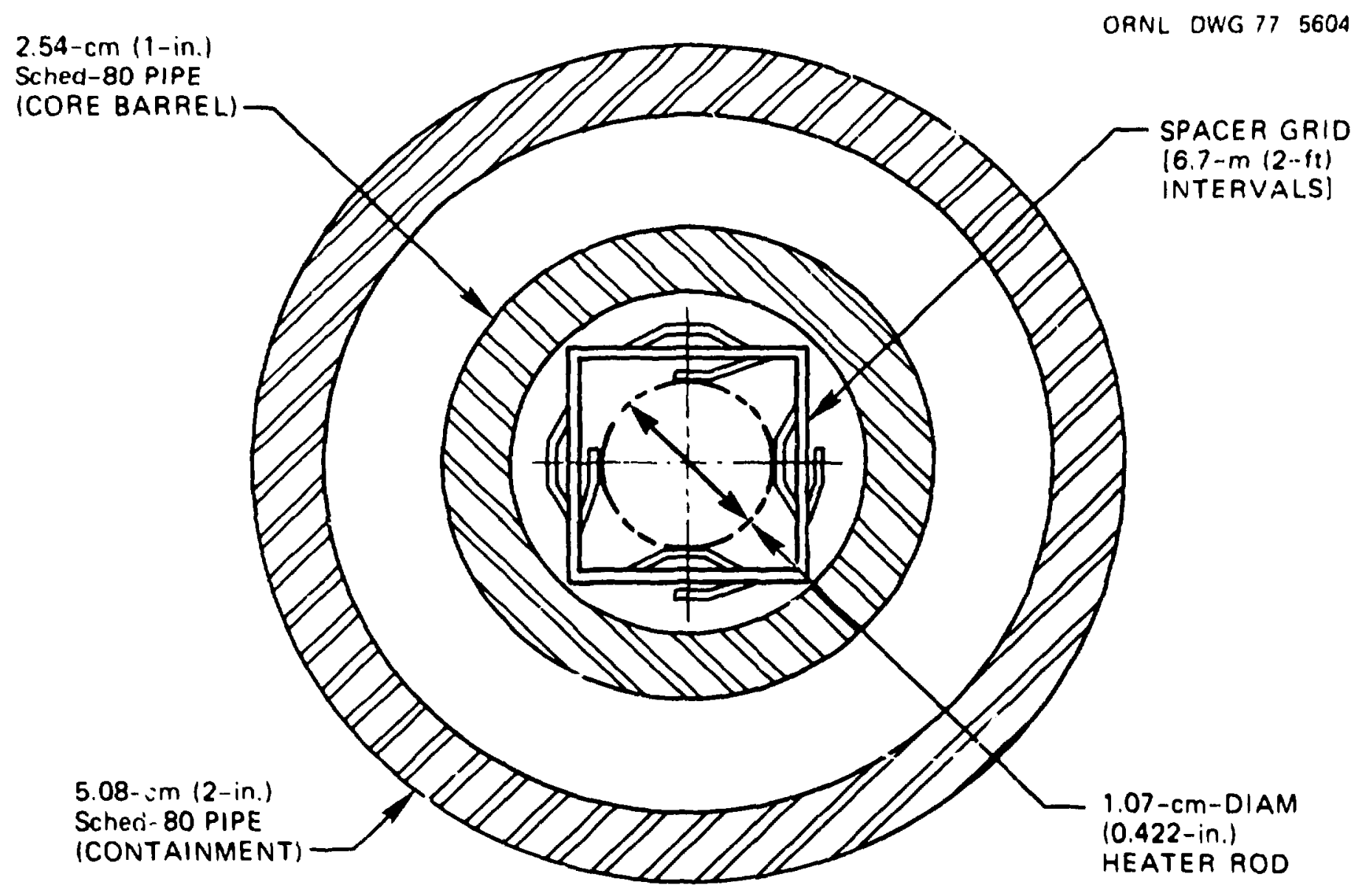

Fig. 3.2. Cross-sectional view of current FCTF test section. 


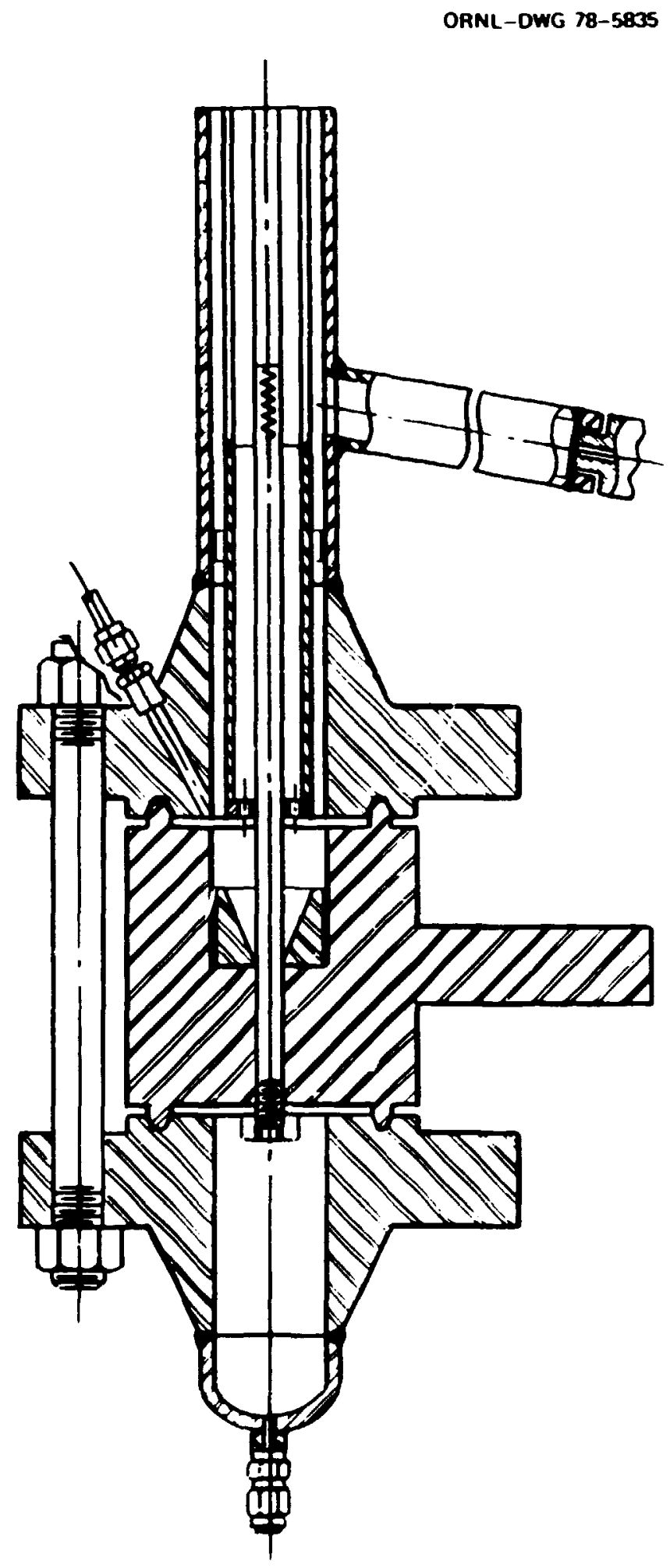

Fig. 3.3. Cross-sectional view of bottom of FCTF test section. 

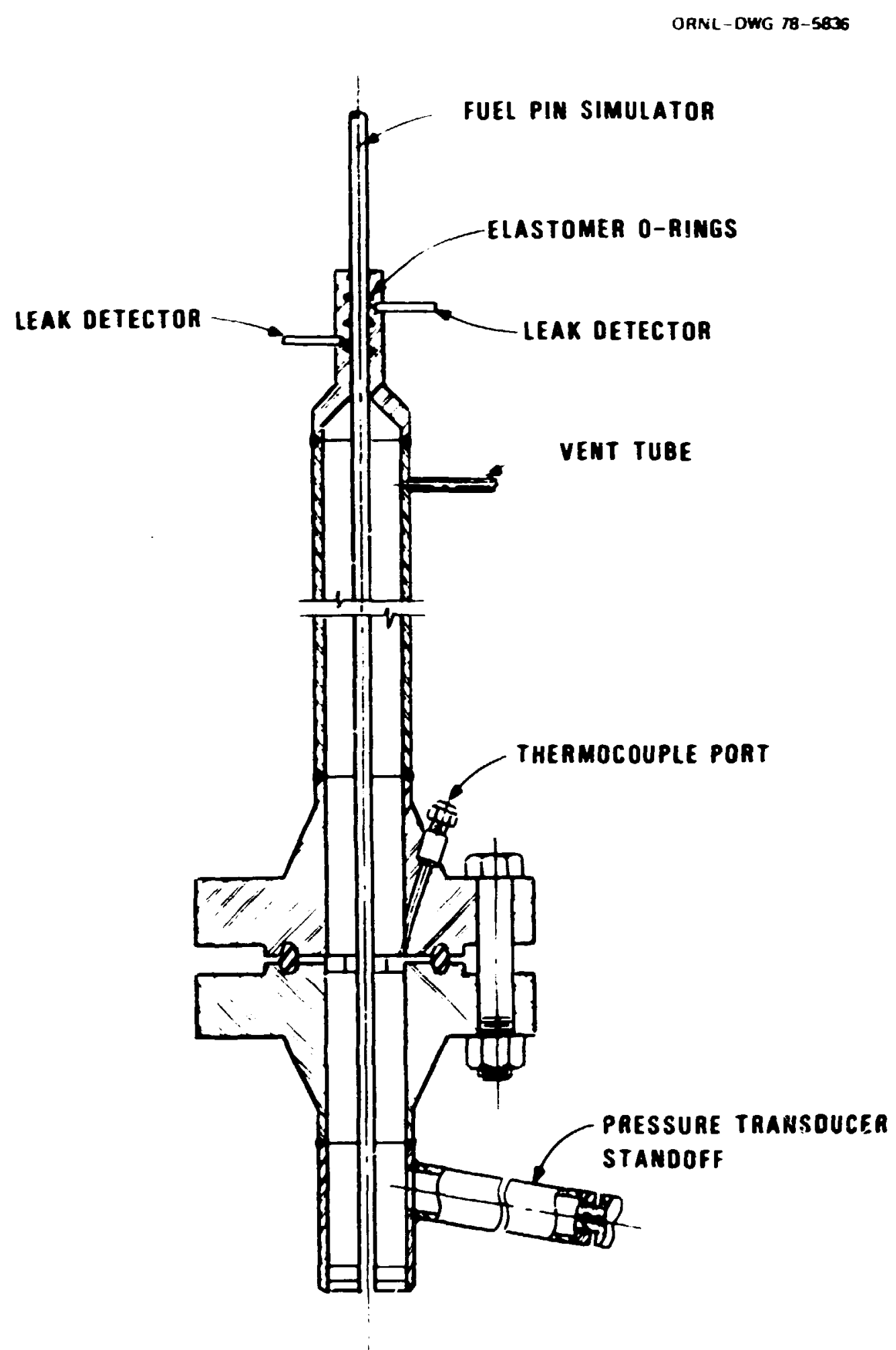

Fig. 3.4. Cross-sectional view of FCTF 0-ring seal assembly. 


\subsection{Steady-State Operation}

The Westinghouse $100 \mathrm{~A}$ canned rotor pump delivers $1.26 \mathrm{dm}^{3} / \mathrm{sec}(20$ gPm) of demineralized water to the test section, and external loop heaters maintain the test section inlet water temperature at $561 \mathrm{~K}\left(550^{\circ} \mathrm{F}\right)$. The water flows into the test section, down the outside of the core barrel, and then up the inside of the core barrel through the annular regicn surrounding the heater. The mass velocity of water flowing by the heater is about $1360 \mathrm{~kg} \mathrm{~m}^{-2} \mathrm{sec}^{-1}\left(10^{6} 1 \mathrm{~b} \mathrm{hr}^{-1} \mathrm{ft}^{-2}\right)$. The water then flows from the test section through an instrument line containing pressure transducers, thermocouples, a drag disk, a densitometer, and a turbine meter. A pressurizer maintains the loop pressure at $15.5 \mathrm{mN} / \mathrm{m}^{2}$ (2250 psi). In its present configuration, the FCTF has a minimum volume/power ratio of $0.21 \mathrm{~m}^{3} / \mathrm{MW}$ and only single-ended cold-leg break tests are possible.

\subsection{Blowdown Operation}

A blowdown is initiated by overpressurizing the rupture disk station. After both disks rupture, flow through the test section reverses and exits the loop through a "break area" orifice imm 2diately upstream of the upstream rupture disk. The drag disk and turbine meter indications demonstrate that reversal is very rapid witi no rereversal of flow. The fluid in the inlet (cold-1 28 ) side of the loon can communicate with the break by flowing around the core barrel rather than flowing back through the heat exchanger, instrumen'. line, and test section. No flow instrumentation is in the cold-leg side at this time. Before the blowdown, the pressurizer can be valued out of the system if desired.

Heater power is maintained at the pre-blowdown level until a portion of the heater enters a CHF regime. At the onset of $\mathrm{CHF}$, the heater sheath thermscouple outputs increase at a rate of about $110 \mathrm{k} / \mathrm{sec}\left(200^{\circ} \mathrm{F} / \mathrm{sec}\right)$ until they reach a predetermined temperature. At this time, overtemperature trip monitors turn off the heater current. Thirty seconds after blowdown initiation, a fine mist of water flows from a $r$ ing at the top of the test section, entering at about $300 \mathrm{~K}\left(80^{\circ} \mathrm{F}\right)$ and $12.6 \mathrm{~cm}^{3} / \mathrm{sec}(0.2$ $\mathrm{gPm})$, and queriches the heater. 


\subsection{Data Acquisition System}

The data acquisition system consists of a PDP-8/E computer with a teletype output. Programs are stored on the disk for on-line statistical analyses of the daca. Immediately after a blowdown, photographs may be made of the transient data displayed on the scope. The system scans at a rate of 10,000 channels per second. In the present operational mode, approximately 70 instruments - pressure transducers, thermocouples, flow indicators, etc. - are monitored 10 times per second. 


\section{PERFORMANCE TESTS OF FUEL PIN SIMLLATORS}

\subsection{Summary cf Experimental Testing Program}

A total of 11 electrical fuel pin simulators have been tested. After preliminary nondestructive tests, each heater was installed in the FCTF and was submitted to a battery of performance tests as shown in Table 4.1. A typical test sequtnce included ( 1 ) steady-state tests in which the heater was operated at several steady-state points to determine repeatability of per ormance; (2) power drop tests in which the heater power was dropped

Table 4.1. Paraneters measured or calculated during testing program

I. Nondestructive Testing Prior to Blowtom Test ing

A. X-ray radiography

1. Density variations in $B N$ and $Y g O$

2. Location of heat flux zones - proper heat flux profile

3. Resistance element eccentricity

4. Location of therwocouple junctions

5. Location of breaks in thermocouples

6. The1 - ocouples out of grooves

B. Infrared scans

1. Core transient

2. Clad transient

3. Core sttady-state - proper heat flux profile

c. Thermal search of chermocouple junctions (axial and circumf erent (al)

II. Testing in Single-Rod Facilicy (FCTF)

A. Thermal performance

1. Reproducibility of chermocouple nutput

2. Repeatability of radial $C T$

3. Reproducibility of cime and location of $\mathrm{CHF}$

4. Time consrants of thermocouples

B. Electrical performance

1. Heacer element resistance

2. Insulation resistance of $\mathrm{MgO}$ and $\mathrm{BN}$

C. Mechanical performance

1. Retention of designed geometry

2. incegrity of heater surface

3. Integrity of power connections

4. Adequacy of heater pressure seals

5. Temperature limits of mechanical integrity

6. Degradation of contact between swaged materials 
to zero to determine the thermal time response of the heater; and (3) blowdown tests in which the heater was subjected to a hear. flux crisis and rewet. After the blowdcwn tests, the heater was removed from the FCTF aad reexamined by nondestructive tests to determine the mecinanical and electrical deterioration. The operational histoiy of each fuei pin simulator tested in the FCTF is surmarized in Table 4.2.

The discussion which follows will address only the resting of fuel pin simulators in the FCTF. Sondestructive testing will be discussed only when used in the measurement of the effect of the FCTF tests.

\subsection{Thermal Performance}

\subsubsection{Reproducibility of thennocouple output}

An important aspect of fuel pin simulator thermal performance is repeatability of themocouple output. If the variations in the outputs from run to run are small under identical conditions of power and cooling, a fuel pin simulator has exhibited very good thermal performance, and the analyst may calculate the surface temperature and heat flux with confidence.

Sowe fuel pin simulators tested in the FCTF, however, showed signif:cant variations in run-to-run steady-state themocouple outputs. The thermocouples generally indicated higher temperatures, with the magnitudes of the variatiuns decreasing with temperature cycling. Bundle 1 prototypes behaved recsonably well, but bundle 1 production heaters showed large shifts in thermocouple temperature indications - sonetimes as large as $50 \mathrm{~K}$ $\left(90^{\circ} \mathrm{F}\right)$. The outputs of the bundle 1 production heater w150-74 are shown in Figs. 4.1 and 4.2, which illustrate that the outp'sts of most of the thermocouples increase from one experiment to the next. The thermocouples in the highest heat flux zones, both interior and sheath thermocouples, exhibited the largest changes in indicated temperatures, as shown in Table 4.3. The axial locations of these thermocouples are shown in Fig. 2.6. Before the first blowdown with production heater W150-74 at a maincained steady-state power level of $144 \mathrm{~kW}$ for $7 \mathrm{hr}$, the outputs of all thermocounles showed insignificant variation as shorn in Figs. 4.1 and 4.2. Similarly, the next time the heater operated at $144 \mathrm{~kW}$, the thermocouple outputs were stable but generaily higher than before the first blowdown. 
Table 4.2. Operational history of Watlow indsect heater assemblies teated in the FCTF

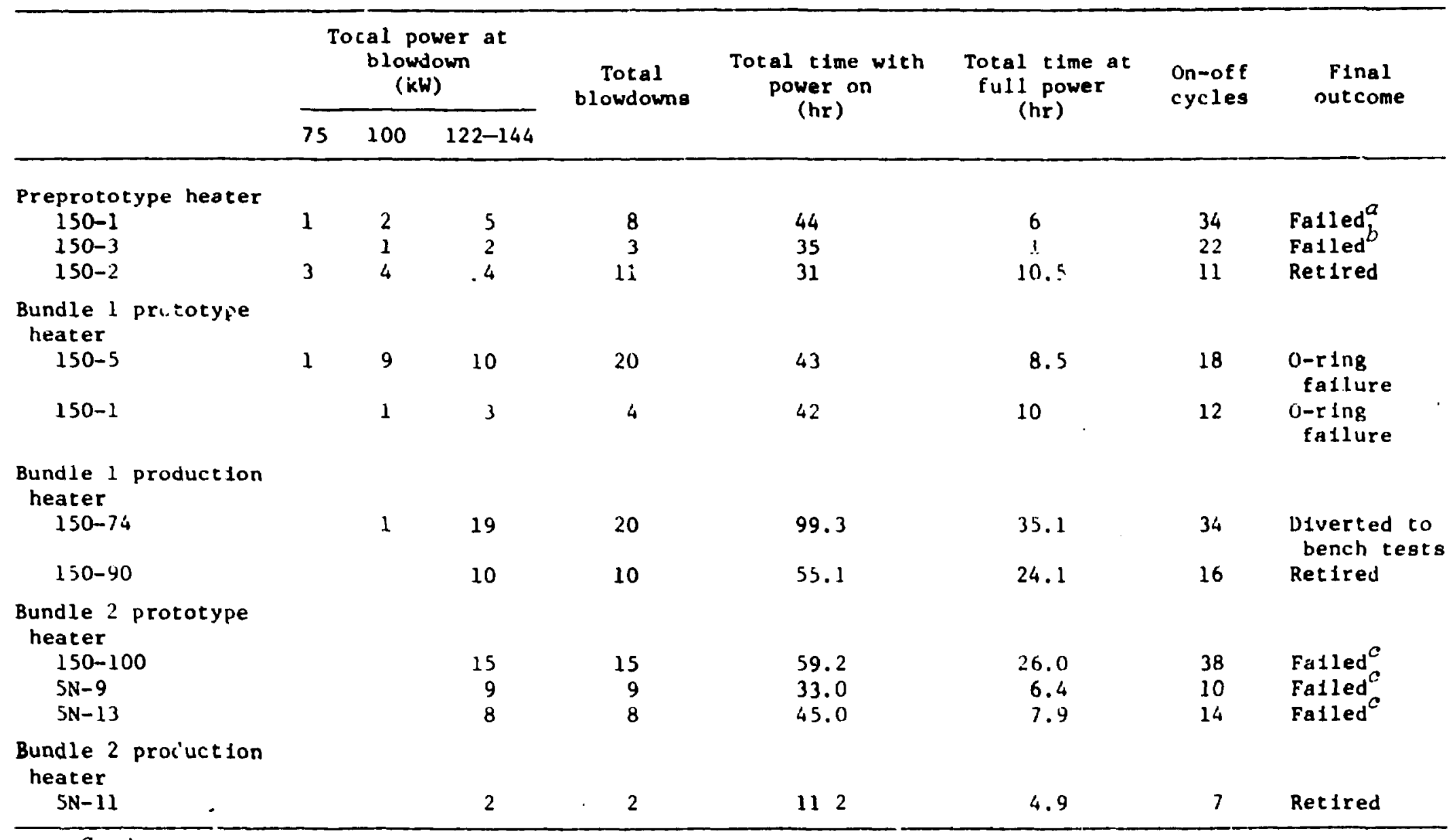

${ }^{a}$ Spit in sheach; sheath damaged by centering screw.

${ }^{b}$ split in sheath.

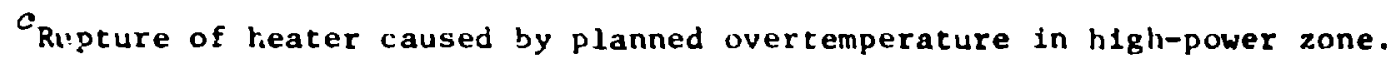


OANI OWC: 75 412!,K

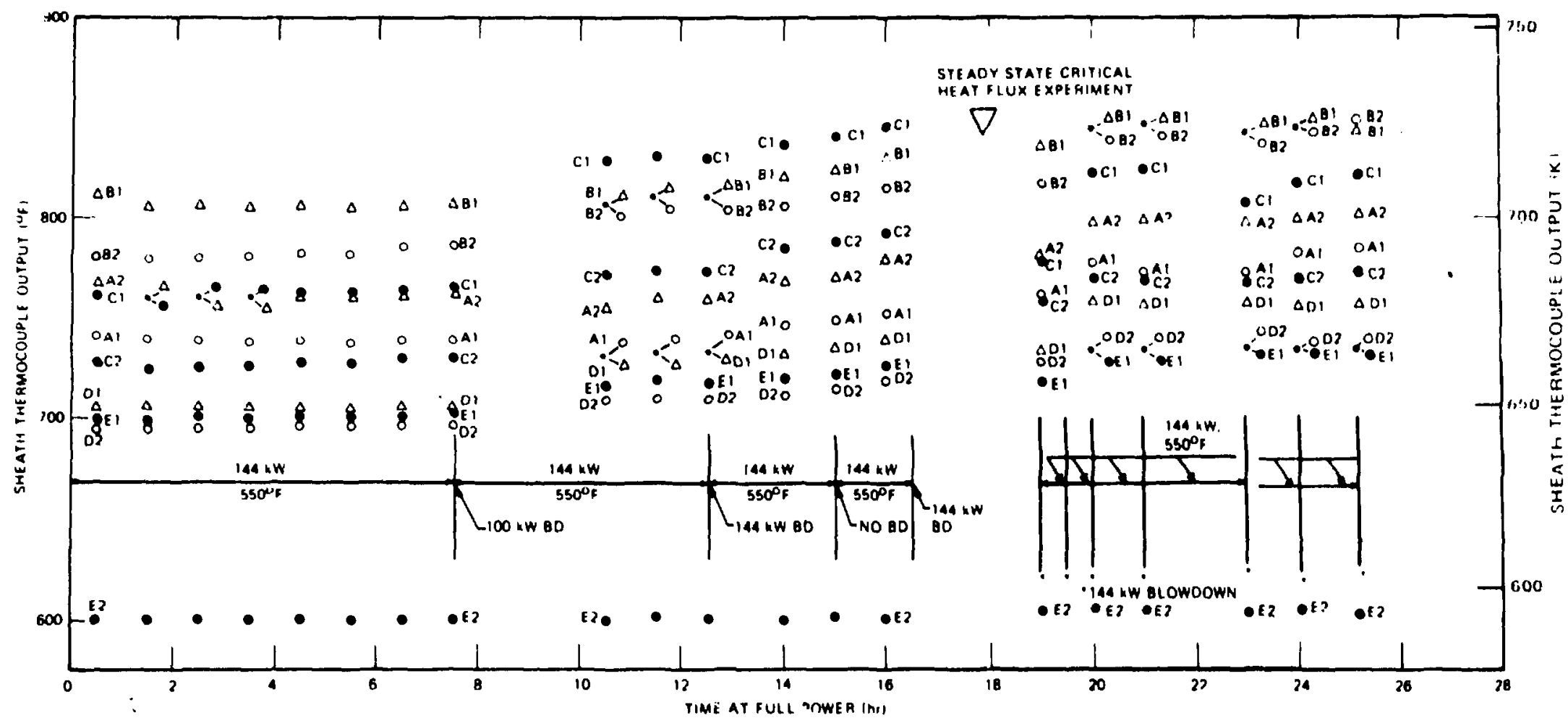

Fig. 4.1. Bundle 1 production heater W150-74 sheath thermocouple outputs as a function of time at full power. 
OANL DWG ?I A12GA

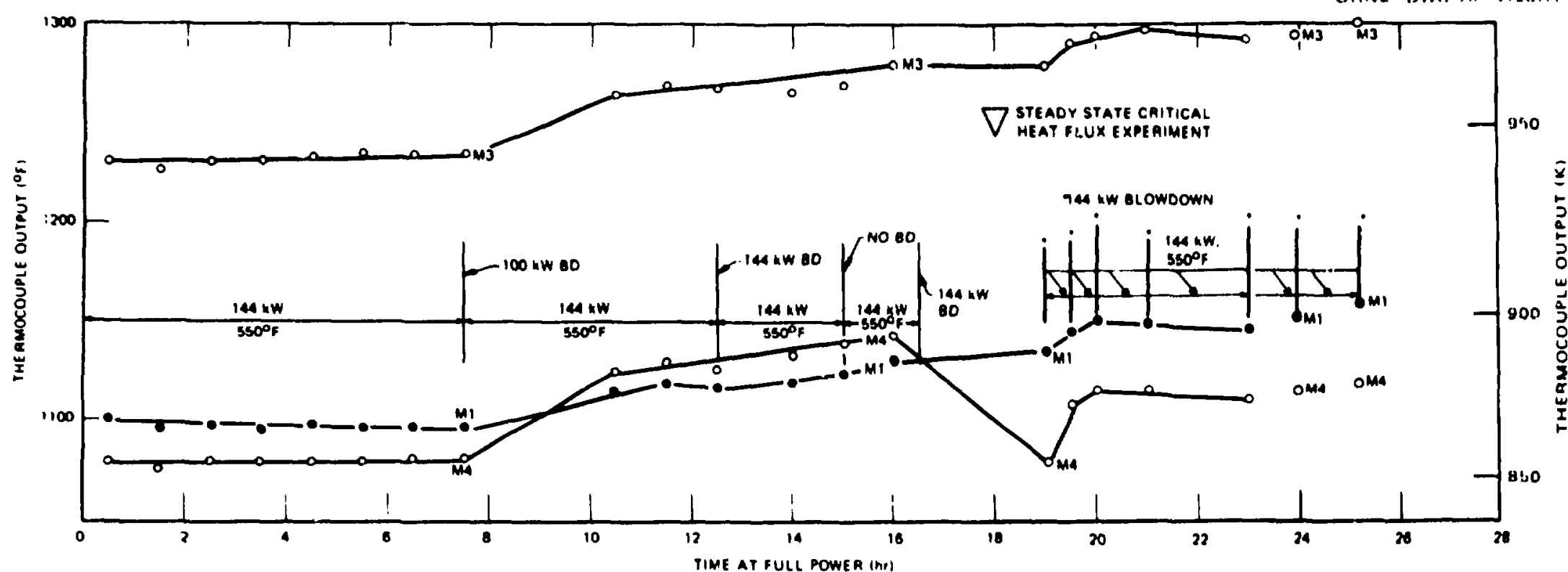

Fig. 4.2. Bundle 1 production heater W150-74 center thermocouple outputs as a function of time at full power. 
Table 4.3. Production heater W150-74 thermocouple output changes at $144 \mathrm{~kW}$ (all $\Delta \mathrm{T}^{\prime} \mathrm{s}$ in $\mathrm{K}$ )

\begin{tabular}{lcrrrr}
\hline P/Pav & $\begin{array}{c}\text { Thermocouple } \\
\text { No. }\end{array}$ & $\Delta \mathrm{T}_{1}$ & $\Delta \mathrm{T}_{2}$ & $\Delta \mathrm{T}_{3}$ & Total $\Delta \mathrm{T}$ \\
\hline 1.06 & $\mathrm{AD}$ & -2.8 & 8.9 & 3.3 & 9.4 \\
1.32 & $\mathrm{AE}$ & -3.9 & 7.2 & 4.4 & 7.8 \\
1.68 & $\mathrm{BF}$ & 0.6 & 7.8 & 2.8 & 11.1 \\
1.68 & $\mathrm{BG}$ & 11.7 & 0 & 2.8 & 14.4 \\
1.68 & $\mathrm{CH}$ & 35.6 & 5.6 & 3.3 & 44.4 \\
1.27 & $\mathrm{CI}$ & 23.3 & 7.8 & 2.8 & 39.4 \\
1.27 & $\mathrm{DJ}$ & 13.3 & 1.7 & 2.2 & 17.2 \\
1.05 & $\mathrm{DK}$ & 7.2 & 2.8 & 1.7 & 11.7 \\
1.05 & $\mathrm{EL}$ & 7.8 & 2.8 & 2.2 & 12.8 \\
0 & $\mathrm{EO}$ & 0 & 1.1 & 0 & 1.1 \\
1.32 & $\mathrm{ME}$ & 11.7 & 4.4 & 4.4 & 20.6 \\
1.68 & $\mathrm{MG}$ & 18.9 & 1.7 & 5.6 & 26.1 \\
1.68 & $\mathrm{MH}$ & 24.4 & 6.1 & 3.3 & 33.9 \\
\hline
\end{tabular}

These results indicate that the trend of increasing temperature is not a steady-state, time-at-temperature effect. The data indicated that some phenomenon during either the blowdown precess or the subsequent heatup was affecting the high-temperature performance of the thermocouples or was in some way affecting the heat transfer characteristics of the heater.

After the second blowdown with production heater W150-74, the next experiment involved operating the heater at $144 \mathrm{~kW}$ for a $\mathrm{few}$ hours and then returning the reater and the loop to ambient conditions slowly without a blowdown. A further increase in thermocouple output resulted, as shown in Table 4.3, column $\Delta \mathrm{T}_{3}$. The average increase was about $2.8 \mathrm{~K}\left(5^{\circ} \mathrm{F}\right)$. These data showed that the varlations in thermocouple outputs were not caused by the mechanics of the blowdown but by thermal cycling of the heater.

Overall changes in indicated temperatures as high as $45 \mathrm{~K}\left(80^{\circ} \mathrm{F}\right)$ at $144 \mathrm{~kW}$ were measured in the sheath in a high-heat-flux zone, where the average indicated temperature was about $700 \mathrm{~K}\left(800^{\circ} \mathrm{F}\right)$. An overall increase of $34 \mathrm{~K}\left(61^{\circ} \mathrm{F}\right)$ occurred at $144 \mathrm{~kW}$ in the interior in a zone where the average temperature is $880 \mathrm{~K}\left(1124^{\circ} \mathrm{F}\right)$. 
The data shown in Figs. 4.1 and 4.2 and in Table 4.3 were taken at the following steady-state conditions:

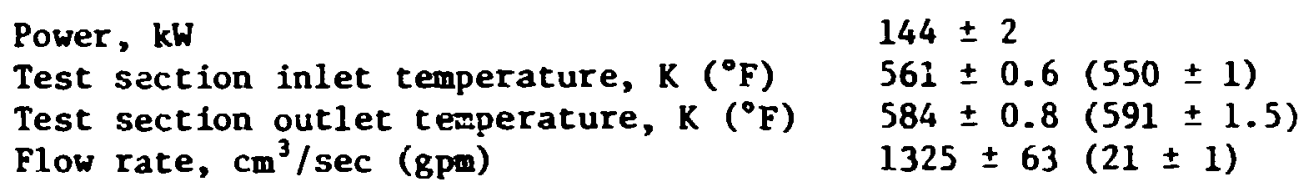

Datı at other lower power levels and lcop temperatures were also measured and compared with similar results. The magnitudes of the run-to-run variations in thermocouple outputs were significant at power levels as low as $60 \mathrm{~kW}$. An example of the trends at several power levels is shown in Fig. 4.3 for sheath thermocouple $B G(P / \bar{P}=1.68)$ in heater W150-74.

Experiments at power levels of 60,100 , and $144 \mathrm{~kW}$ with production heater W150-74, in which (at a constant power level) loop temperature was increased $111 \mathrm{~K}\left(200^{\circ} \mathrm{F}\right)$ and then returned to the original temperature, show that thermal cycling of $111 \mathrm{~K}\left(200^{\circ} \mathrm{F}\right)$ is unfmportant. However, $444 \mathrm{~K}$ $\left(800^{\circ} \mathrm{F}\right)$ changes in sheath and interior temperatures that occur when $a$ heater is deenergized and cooled and then returned to full power and temperature were apparently enough to cause a problem. The fact that the interior temperatures increased with operating experience showed that either the rhermocouples deteriorated in high-temperature performance or that some deterioration in the heat transfer path occurred. For each run, however, all thermocouples were checked at $294 \mathrm{~K}\left(70^{\circ} \mathrm{F}\right)$ and $422 \mathrm{~K}\left(300^{\circ} \mathrm{F}\right)$ with the heater deenergized. The indicated temperatures of all heater thermocouples agreed within $1.7 \mathrm{~K}\left( \pm 3^{\circ} \mathrm{F}\right)$ of each other at these isothermal states. The high-temperature performances of the thermocouples were not checked in isothermal tests because of physical loop operating restrictions. However, the excellent lower temperature agreement among the thermocouples suggested that they were probably in good condition at elevated temperatures also.

Thus, a deterioration in the heat transfer path from the heater resistance element to the water seemed a more likely alternative. The fact that the sheath thermocouples showed large overall increases in the prototypical and production heaters suggested that the problem did not originate in the boron nitride insulation, in the magnesium oxide inner core, or in the 


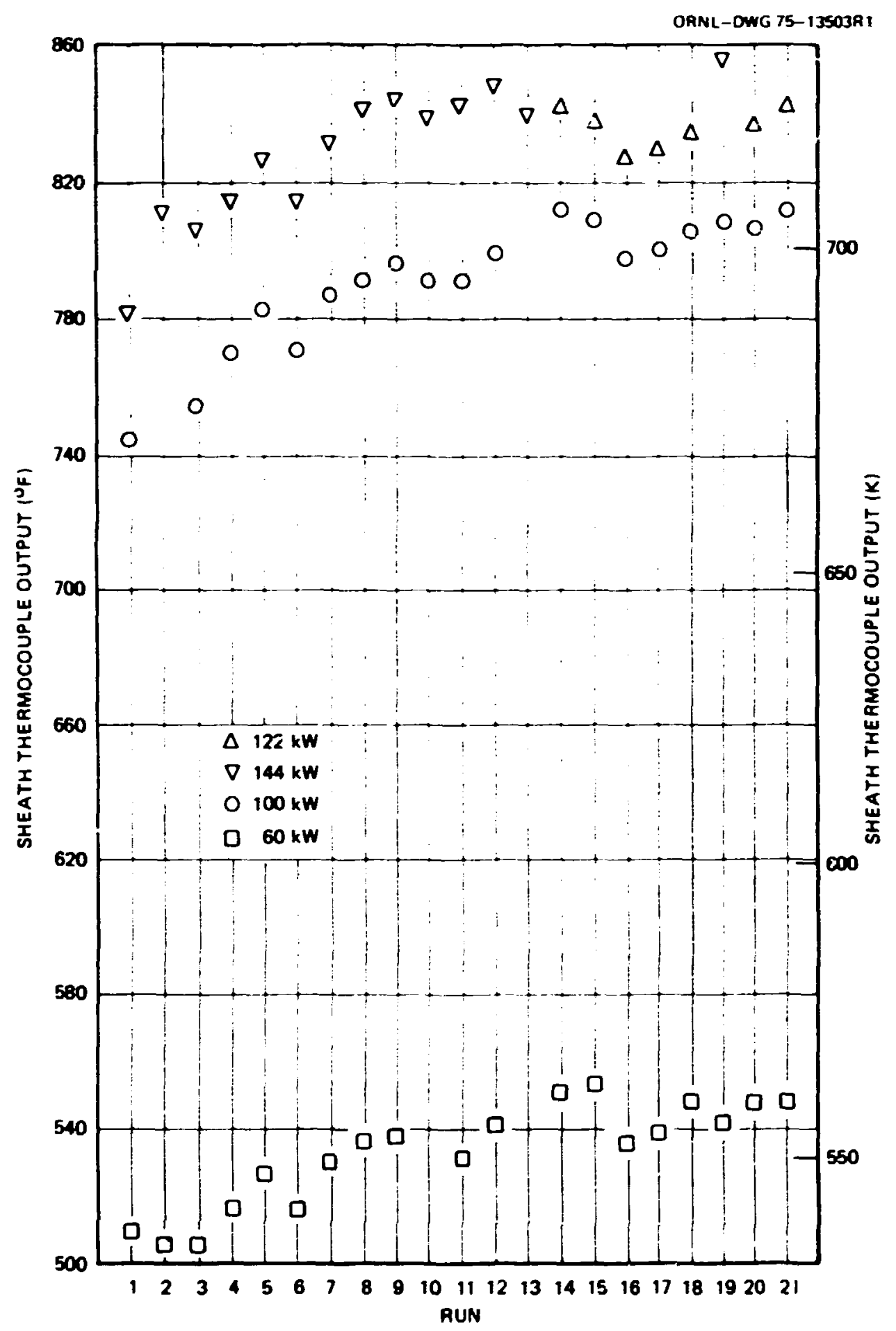

Fig. 4.3. Run-to-run sheath thermocouple output variations for different power levels (bundle 1 production heater w150-74). 
change from Incoloy to Inconel. A change in thermal impedance through the double-walled sheaths into the water was a more probable occurrence. This change in thermal impedance would have to be caused by changes in gap conductivity and/or changes in the heat transfer coefficient from the heater surface to the water. Visual examinations of the surfaces of all heaters removed from the FCTF, however, indicated no significant film or other foreign substance to introduce a fouling coefficient. The data suggested that the gap conductance through the double-walled sheaths changed as the sheath temperatures cycled from operating temperatures of $700 \mathrm{~K}\left(800^{\circ} \mathrm{F}\right)$ down to ambient temperatures of $294 \mathrm{~K}\left(70^{\circ} \mathrm{F}\right)$ and returned to $700 \mathrm{~K}\left(800^{\circ} \mathrm{F}\right)$. The cause of the increases in thermocouple outputs was fiscovered to be the generation and subsequent growth of gaps between the inner and outer sheaths of the fuel pin simulators as shown in Fig. 4.4. During heating, the fuel pin simulator expands radially with the apparent resultant plastic deformation of the outer sheath. During cooling, the outer sheath does not contract as much as the rest of the simulator and a gap results, causing an increase in thermal resistance during the next approach to power and operating conditions. Since the sheath thermocouples are welded to the inner sheath, their outputs indicate that the higher temperatures at the inner sheath are caused by the increased thermal zesistance from the inner-toouter sheaths.

The data for the second bundle 2 prototype showr in Table 4.4 indicate that the output of the thermocouples in the $F, G, H$, and $J$ levels increased from experiment to experiment, with most of the increases occurring from the first to the second experiment. The axial locations of the thermocouples are shown in Fig. 2.7. This trend is similar to that observed during testing of bundle 1 heaters. However, the magnitudes of the increases in bundle 2 heater thermocouple outputs are significantly smaller than those of bundle 1 heaters. The outer sheath of a bundle 2 heater is 1.5 times as thick as that of a bundle 1 heater, which probabiy results in lower hoop stresses when the heater is operating at high temperatures. The relaxation of the outer sheath, which causes the gap to grow between the sheaths, probably will be less severe with bundle 2 than with bundle 1 heaters. 


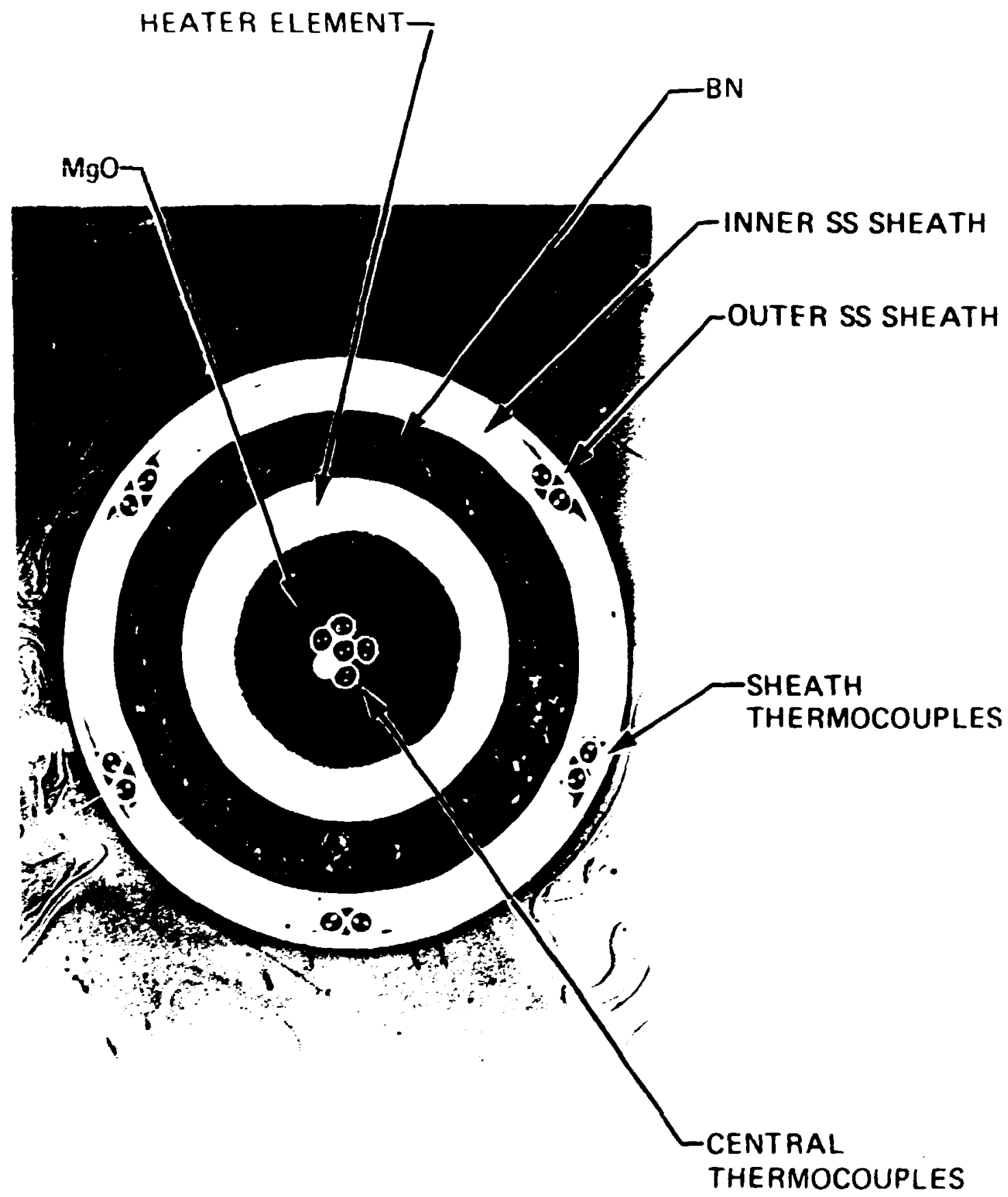

Fig. 4.4. Cross section of bundle 1 prototype BDHT fuel pin simulator showing gap between inner and outer sheaths. 


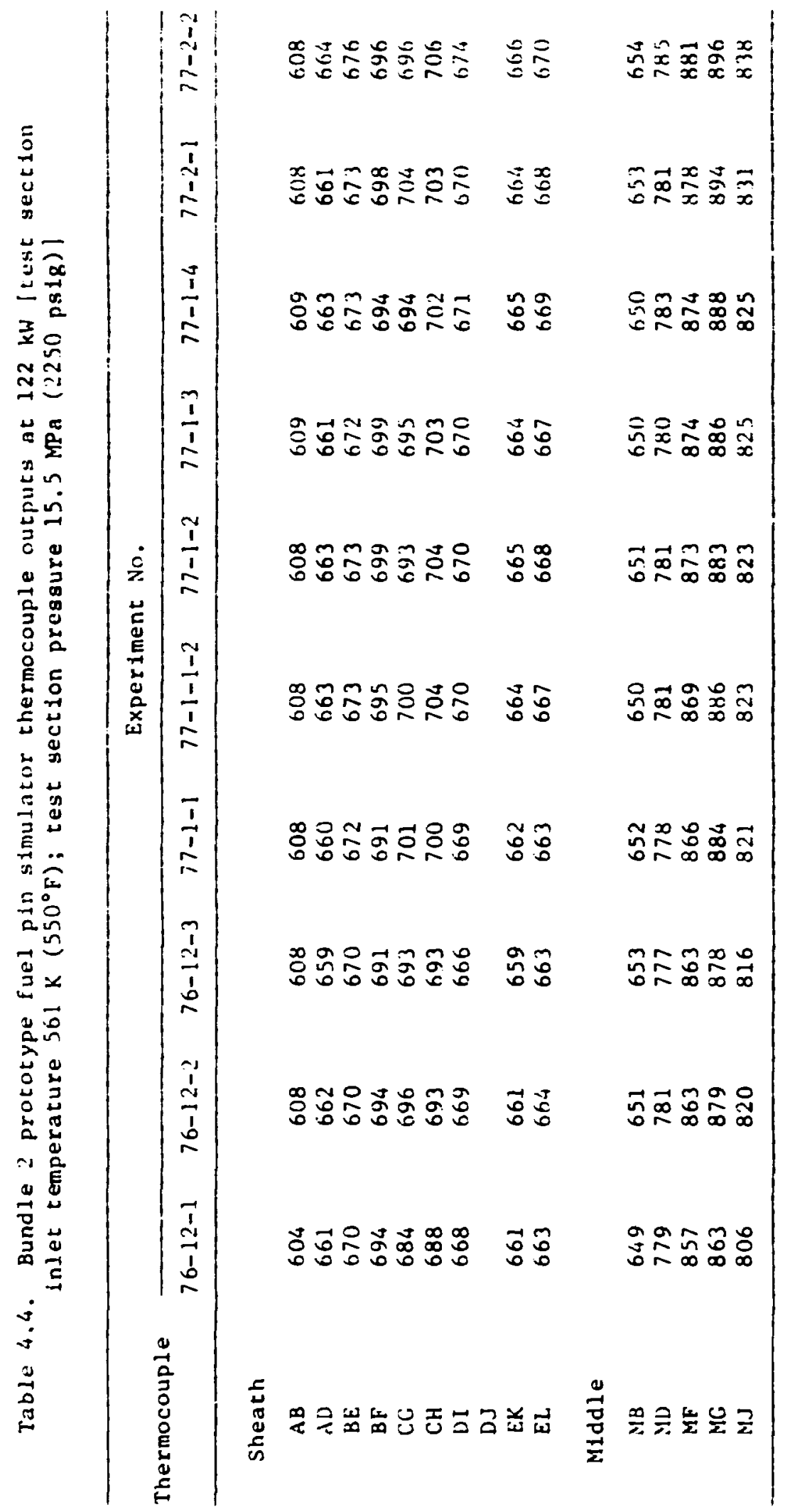




\subsubsection{Repeatability of radiil $\Delta T$}

One measure of the thermal performance of a fuel pin simulator is the repeatability of the radial temperature difference between center and sheath thermocouples at approximately the same axial level. A plot of radial $\Delta T$ vs rod power should be a straight line with a slope proportional to the heat flix at any particulai level. Since the sheath thermocouples are spot-welded to the outer surfaces of the grooves of the inner sheath, the center-to-sheath thermocouple $\Delta T$ is insensitive to the gap between the sheaths and to the heat transfer coefficient at the heater surface. This radial $\Delta T$, therefore, is a measure of the thermal conductance from the MgO inner core to the outer surface of the irner sheath. Parameters determining this conductance are the contact coefficients at the interfaces between the heating element and $B N$ and the inner sheath and $B N$ and the effective thermal conductivities of the heating element, $B N$, and the inner sheath.

The data plotted in Fig. 4.5 show radial $\Delta T$ as a function of heater power for the bundle 2 prototype $6150-100$. The two groups of data represent two power zones where the ratios of local to average heat flux are 1.7 and 1.3. These zones contain a total of five center and five sheath thermocsuples. The results of only two center-to-sheath $\Delta T$ plots are shown for clarity. These data were taken during the first, second, and sixth approaches to full power. If the $\Delta T$ values are normalized by cal-

culating $\Delta T$ ( $\left.\mathrm{P}_{\text {local }} / \mathrm{P}_{\mathrm{av}}\right)$ and plotted vs total rod power, the result is the linear relationship shown in Fig. 4.6. Each data point in the figure is the average of several measurements taken during six approaches to full power with subsequent blowdowns. Average values of normalized radial $\Delta T$ are shown in Table 4.5. Except for the 60 - and $90-\mathrm{kW}$ points for level $\mathrm{F}$, the normalized data are well represented by a straight line. Note that the variances in the level $F$ data at 60 and $90 \mathrm{~kW}$ are larger than those of the other levels; the reason for this is not known. A large variation in radial $\Delta T$ at different axial leveis in the same heat flux zone, however, is not uncommon. For instance, the data in Fig. 4.7 show how the values of radial $\Delta T$ for two different axial levels in the same heat flux zone differed during the same run with the first bundie I prociuction line heater tested in the FCTF. 


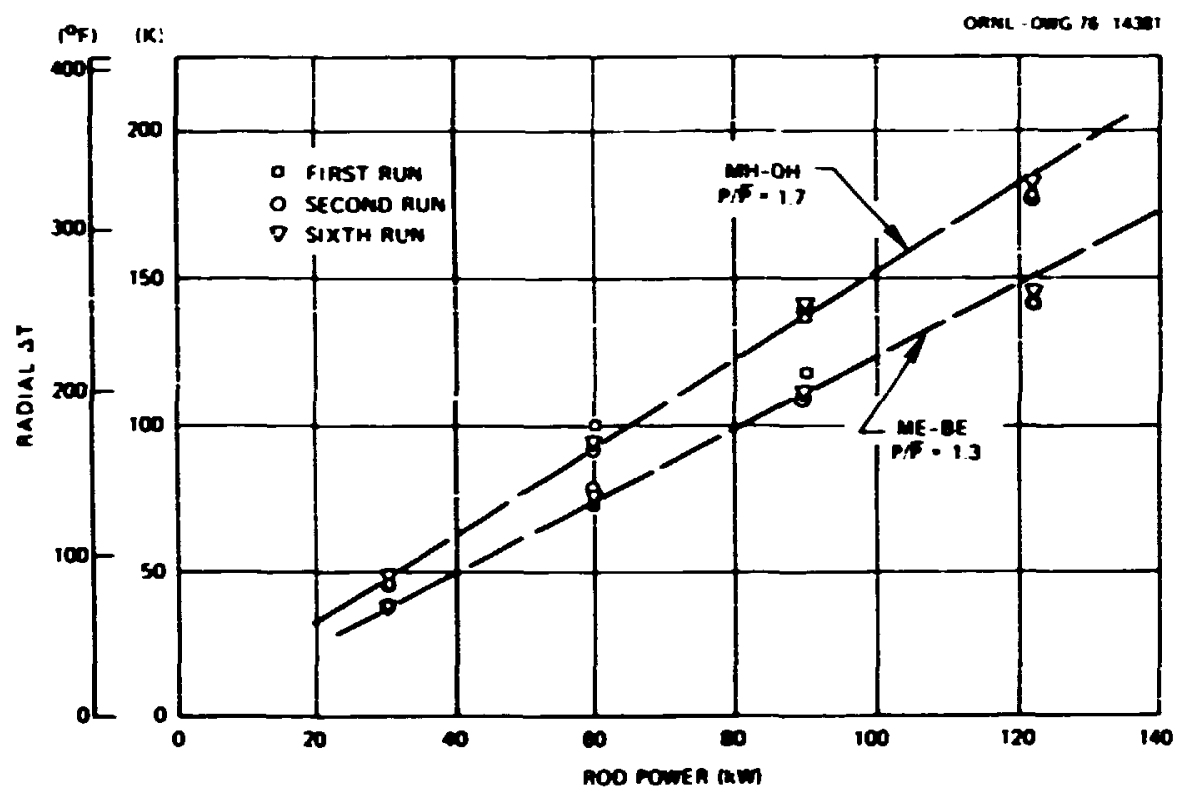

Fig. 4.5. Radial $\Delta T$ as a function of rod power for heater w150-100 (bundle 2 prototype).

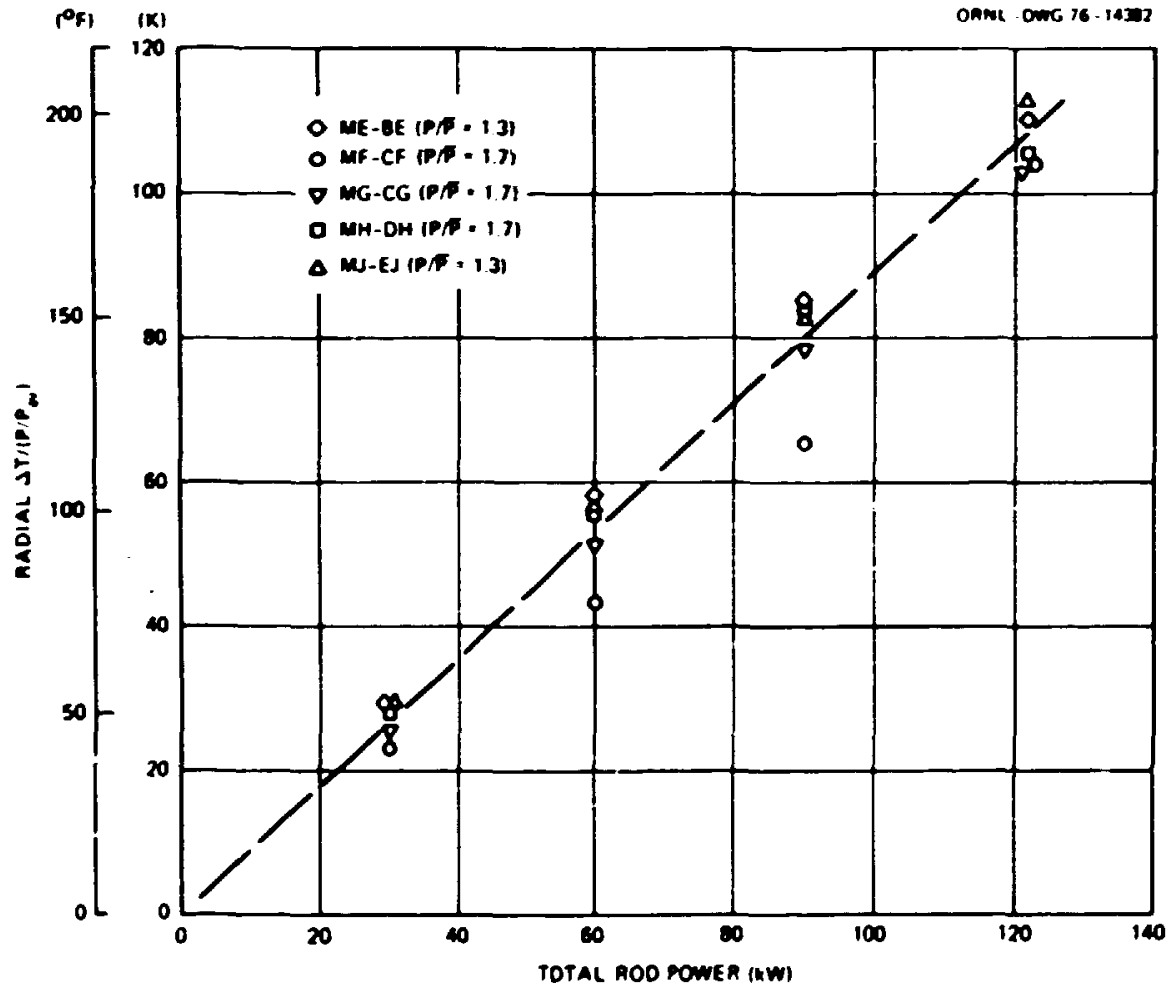

Fig. 4.6. Radial $\Delta T /\left(\mathrm{P}_{\text {local }} / \mathrm{P}_{\mathrm{av}}\right)$ as a function of total power for bundle 2 prototype heaters. 
Table 4.5. Purmalized radial it us power fir bund le 2 protorype

\begin{tabular}{|c|c|c|c|c|c|}
\hline $\begin{array}{c}\text { Total rod } \\
\text { power } \\
\text { (kw) }\end{array}$ & $\begin{array}{l}\text { Axial } \\
\text { level }\end{array}$ & $\mathrm{P} / \overline{\mathrm{P}}$ & $\begin{aligned} \bar{X}= & \therefore T:(P \cdot \vec{p}) \\
& (K)\end{aligned}$ & $\begin{array}{l}s_{X} \\
(K)\end{array}$ & $\begin{array}{l}\text { Sumber of } \\
\text { neasurements }\end{array}$ \\
\hline 30 & $\begin{array}{l}E \\
F \\
\mathbf{G} \\
H \\
J\end{array}$ & $\begin{array}{l}1.3 \\
1.7 \\
1.2 \\
1.7 \\
1.3\end{array}$ & $\begin{array}{l}29.7 \\
22.9 \\
25.4 \\
28.1 \\
29.8\end{array}$ & $\begin{array}{l}0.4 \\
2.5 \\
0.5 \\
0.7 \\
0.4\end{array}$ & $\begin{array}{l}5 \\
5 \\
5 \\
4 \\
5\end{array}$ \\
\hline 60 & $\begin{array}{l}\text { E } \\
F \\
G \\
\text { hi } \\
J\end{array}$ & $\begin{array}{l}1.3 \\
1.7 \\
1.7 \\
1.7 \\
1.3\end{array}$ & $\begin{array}{l}58.3 \\
43.4 \\
51.3 \\
55.3 \\
57.2\end{array}$ & $\begin{array}{l}1.7 \\
3.5 \\
1.2 \\
1.7 \\
1.2\end{array}$ & $\begin{array}{l}5 \\
5 \\
5 \\
5 \\
5\end{array}$ \\
\hline 90 & $\begin{array}{l}E \\
\boldsymbol{E} \\
\mathbf{G} \\
\mathbf{H} \\
\mathrm{J}\end{array}$ & $\begin{array}{l}1.3 \\
1.7 \\
1.7 \\
1.7 \\
1.3\end{array}$ & $\begin{array}{l}85.4 \\
65.3 \\
78.2 \\
84.2 \\
83.2\end{array}$ & $\begin{array}{l}3.6 \\
7.5 \\
2.4 \\
7.2 \\
1.8\end{array}$ & $\begin{array}{l}6 \\
6 \\
6 \\
6 \\
6\end{array}$ \\
\hline 122 & $\begin{array}{l}E \\
F \\
G \\
H \\
J\end{array}$ & $\begin{array}{l}1.3 \\
1.7 \\
1.7 \\
1.7 \\
1.3\end{array}$ & $\begin{array}{l}110.1 \\
103.8 \\
104.0 \\
105.6 \\
113.0\end{array}$ & $\begin{array}{l}0.9 \\
3.8 \\
2.2 \\
1.3 \\
0.3\end{array}$ & $\begin{array}{l}6 \\
6 \\
6 \\
6 \\
5\end{array}$ \\
\hline
\end{tabular}

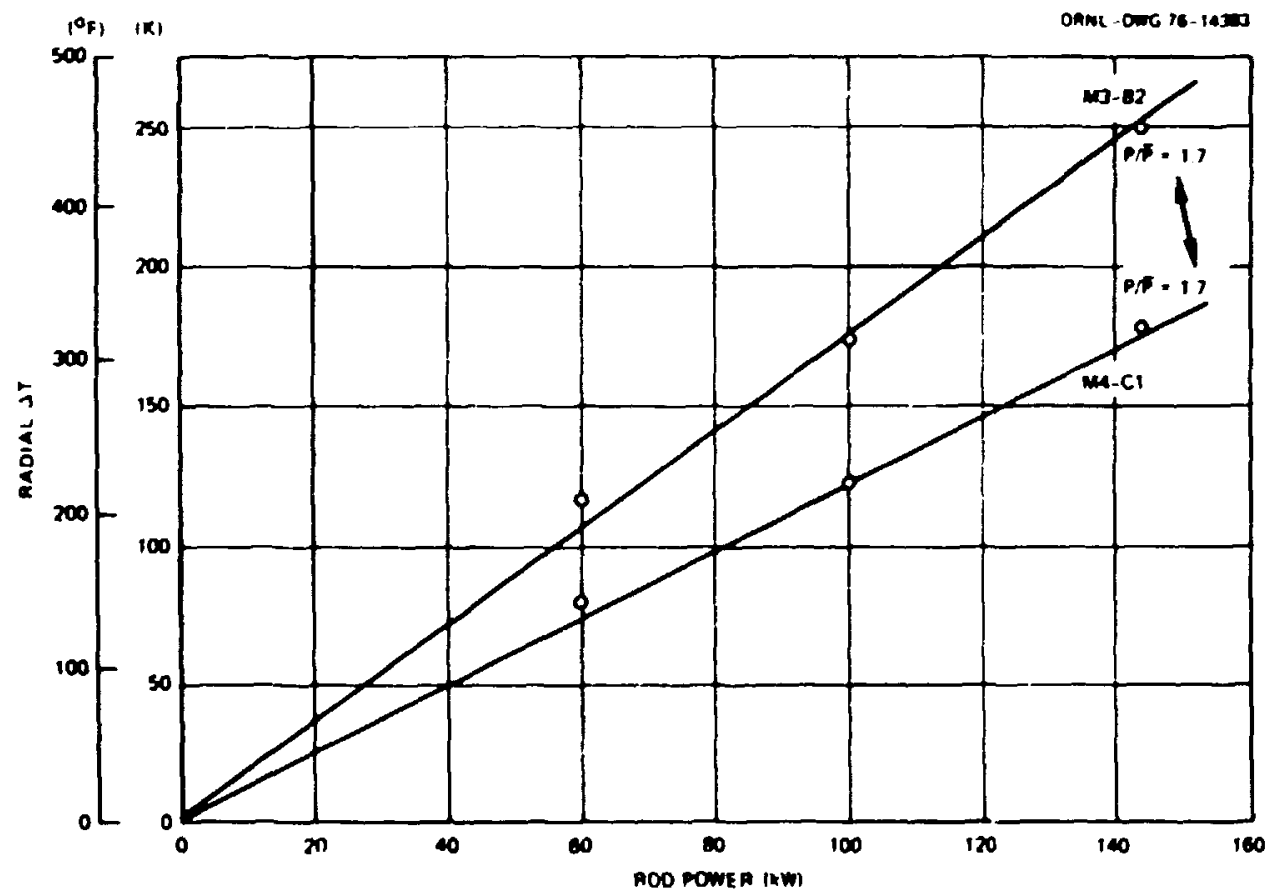

Fig. 4.7. Radial $\Delta T$ in bundle 1 production heater w150-74 in highest power zone. 
The desired thermal performance of a heater is dependent upon the repeatability of these radial $\Delta T^{\prime} s$. This repeatability is a measure of the change in the themral conductance of a heater-during its lifetime. The analyst must have confidence in this value of thermal conductance in order to calculate temperature profiles of high reliability. Furthermore, large changes in radial $\Delta T$ indicate that significant mechanical changes inside the heater may have taken place. No correlation between such changes and heater failure have been made at this time because all observed heater failures have been caused by failure of the outer and inner sheaths with resultant admission of moisture. If a heating element fails, however, a prior indication of failure by significant changes in radial $\triangle T$ is likely.

An eximple of thange in $\Delta T$ as a result of mechanical deterioration is shown in Fig. 4.8. A preprototypical heater for bundle 1 (W150-2) was

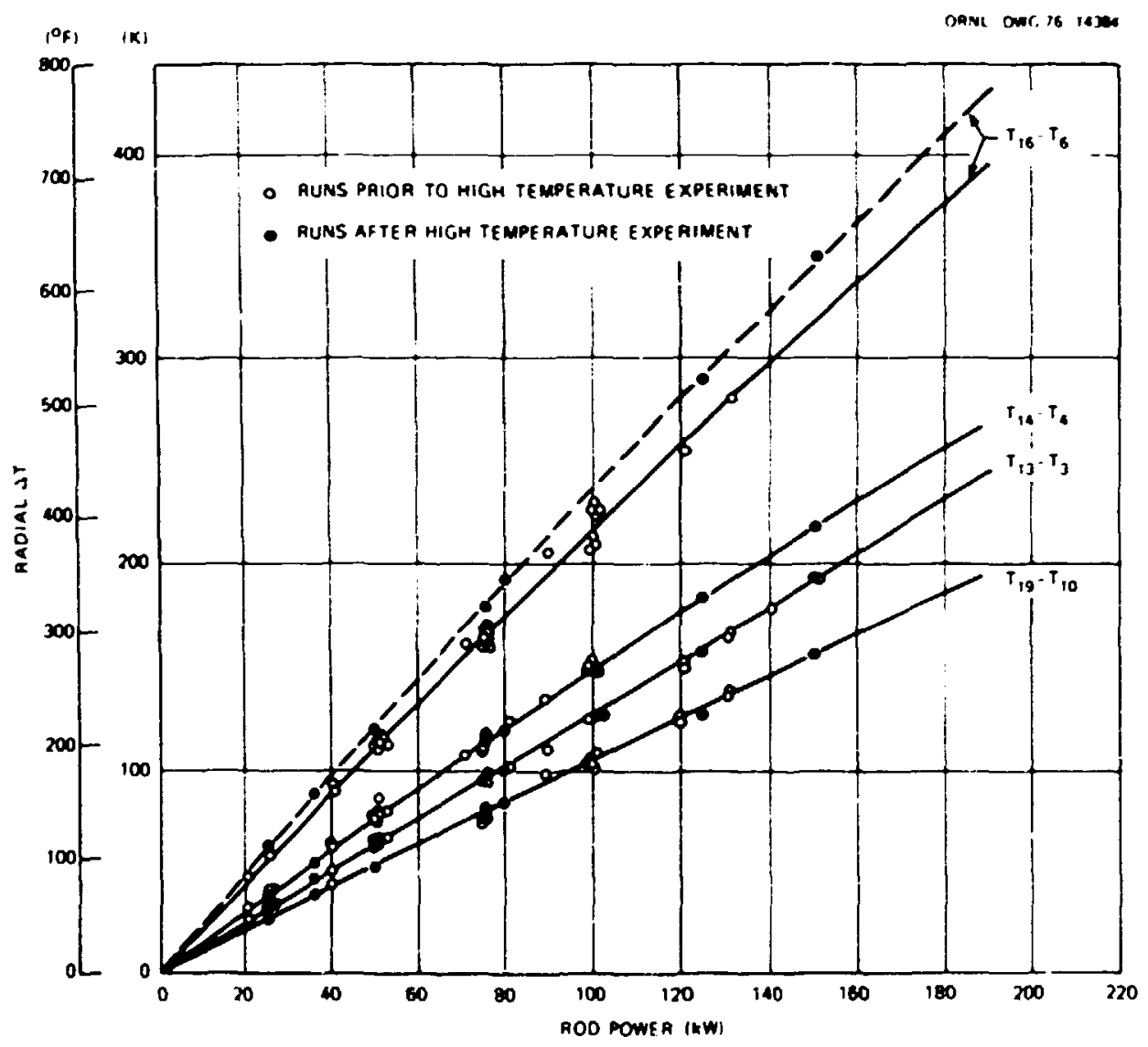

Fig. 4.8. Thermal performance of preprototypiral heater w150-2. 
operated for several runs and then operated to achieve a temperature of about $1300 \mathrm{~K}$ for $1 \mathrm{hr}$. During the next approash to power, the radial II in the highest heat flux zone was significantly higher than before. Shen the heater was removed from the test section, an S-shaped bend was observed in the highest power zone, indiraing severe mechanical defomation of the heating element.

A furcher example of anomalous radial $i T$ is power relationship is shown in Fig. 4.9. These data, which were taken during the operation of

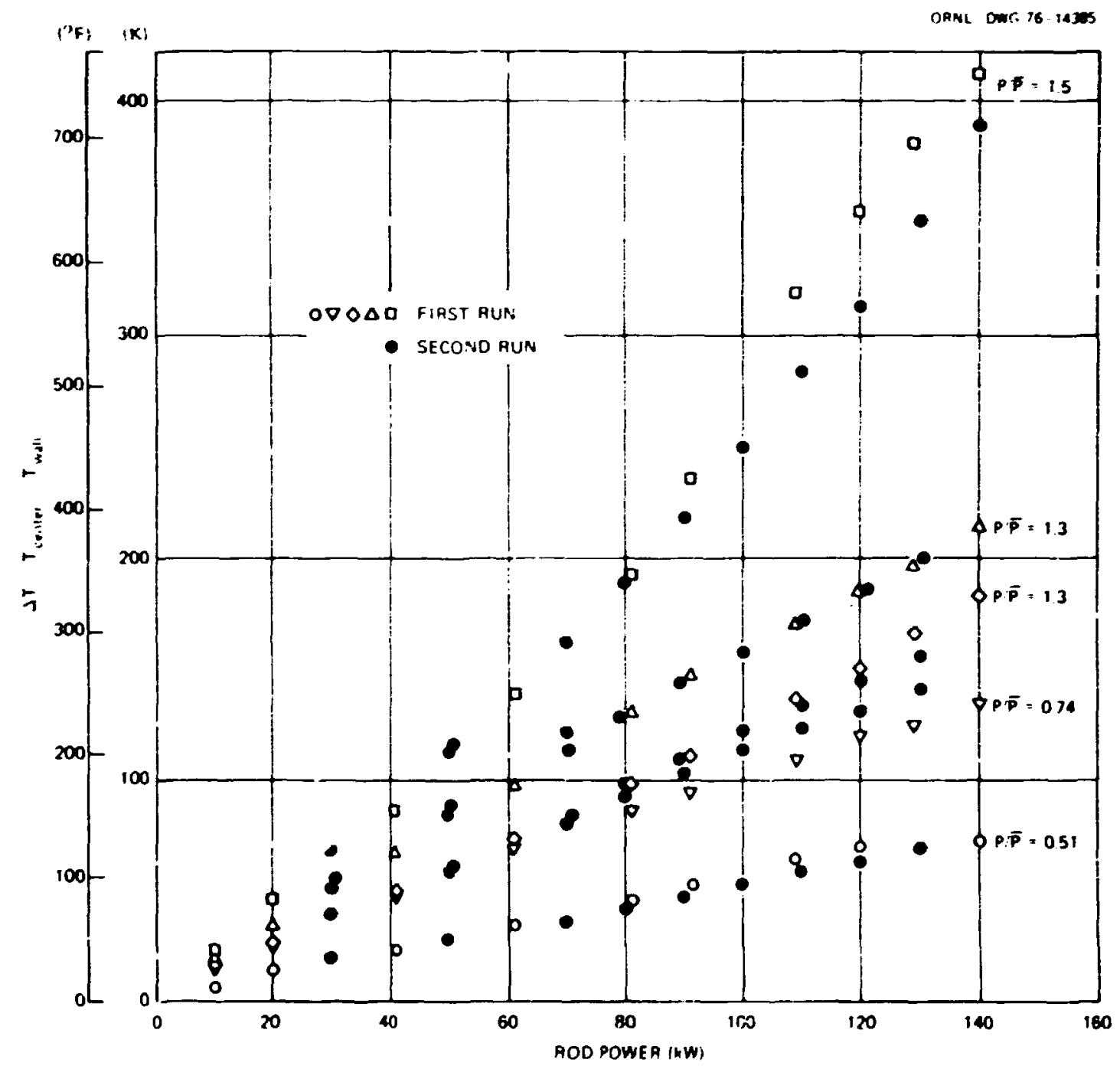

Fig. 4.9. Thermal performance of preprototypical heater w150-3. 
preprctotypical heater w150-3, show a considerable deviation $f_{\text {: }}$ on the expected linear relationship, especially in the high-power zone. Furthermore, the radial $\Delta T$ in the high-power zone was significantly lower in the second approach to power than in the first. Further cycling of power during the second run cid not affect the value of radial $\Delta T$ in any zone. This heater had been rejected during inspection because of poor infrared scans, and blowdown testing was begun only after all other available heaters had been tested.

\subsubsection{Reproducibility of time and location of CHF}

The suitability of BDHT fuel pin simulators for determination of time to CHF and the location of CHF has been demonstrated in the FCTF. For a wide range of blowdown conditions, both the measured time to CHF and the location of CHF repeated very well for each fuel pin simulator tested. The FCTH blowdown test data shown in Tables 4.6 and 4.7 include time to first CHF, first CHF thermocouple designation, distance from lower end of heated zone, loop volume, heater power, break area, pressure at time of $\mathrm{CHF}$, and run number. These data were obtained with an older design of FCTF test section, shown in cross-sectional view in Fig. 4.10. The test section was a concentric annulus formed by a $3.8-\mathrm{cm}-\mathrm{OD}, 3.2-\mathrm{cm}-\mathrm{ID})(1 \mathrm{l} / 2-$ in.-OD, 1 1/4-in.-ID) core barrel inside a pressure housing fabricated from 5.1-cm (2-ín.) s led-80 pipe [ID $=4.93 \mathrm{~cm}(1.939 \mathrm{in.})]$.

Typical pressure and heater temperature traces are shown in Fig. 4.11 for blowdown from $10.34 \mathrm{MN} / \mathrm{m}^{2}$ (1500 psi). The pressure curves labeled outlet and inlet are the outputs of pressure transducers located at the test section outlet and inlet, sespectively. Tha sheath thermocouple traces indicate that CHF conditions began at the level of thermocouple AD approximately $8 \mathrm{sec}$ after blowdown. This thermocouple is the bottom-most thermocouple in the heater and is nearest the test section outlet during a blowdown. The AD thermocouple trace also shows evidence of a rewet and subsequent $\mathrm{CHF}$. As shown by the traces of thermocouples $B F$ and $B G$, the CAF area spreads over the heater with time.

This effect is shcwn more clearly in Fig. 4.12, where the direction of blowdown flow is from the top of the heater to the bottom, or from right to left. The data for the five blowdowns shown include the range of 


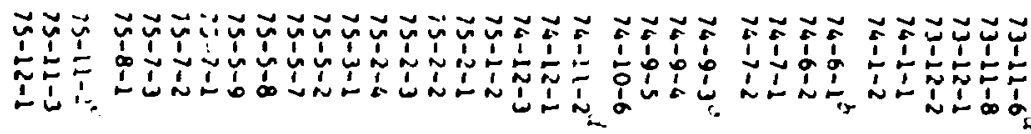

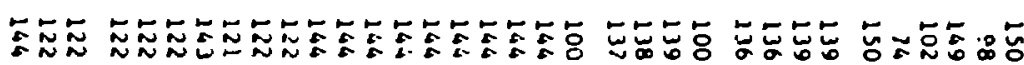

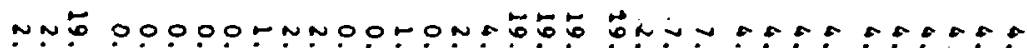

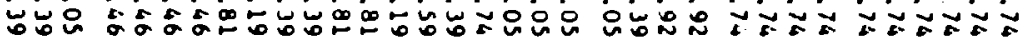
0000000000000000000000000000000000

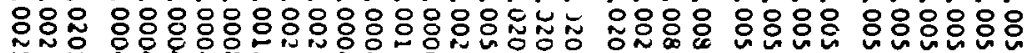

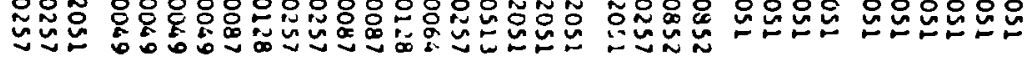

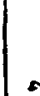

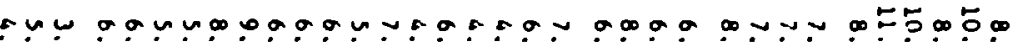

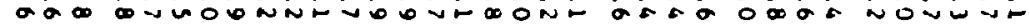

0000000000000000000000000000000000

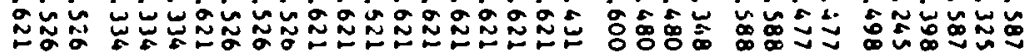

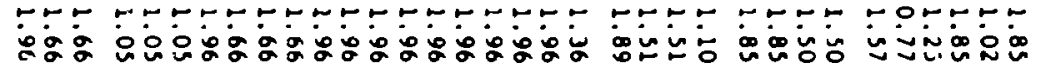

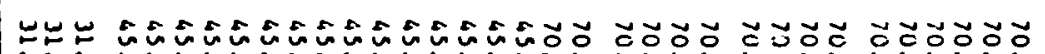

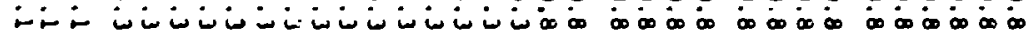

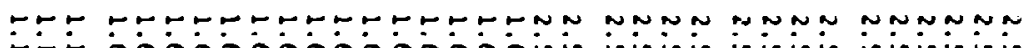

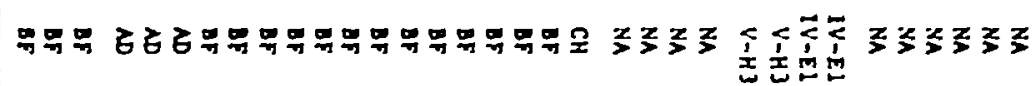

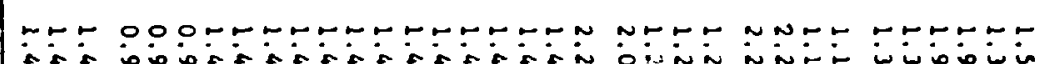

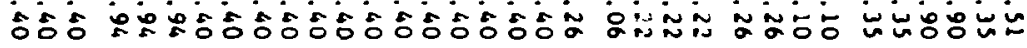

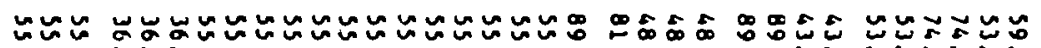
is is is

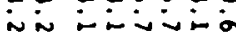

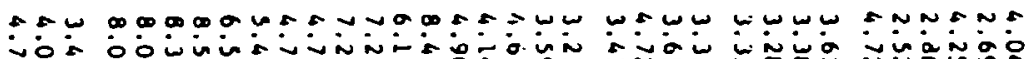

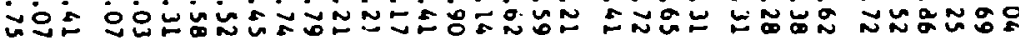

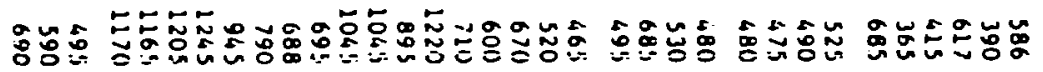

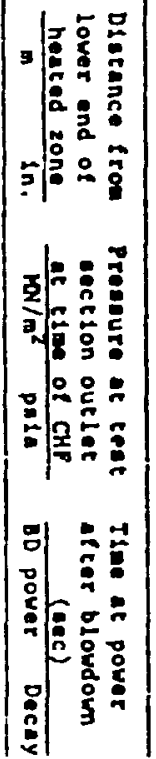

55:

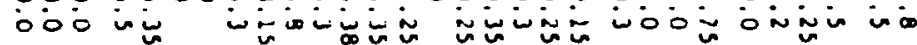

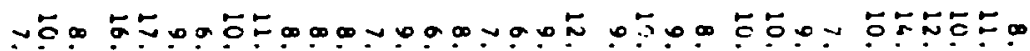

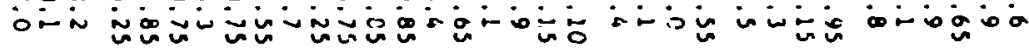




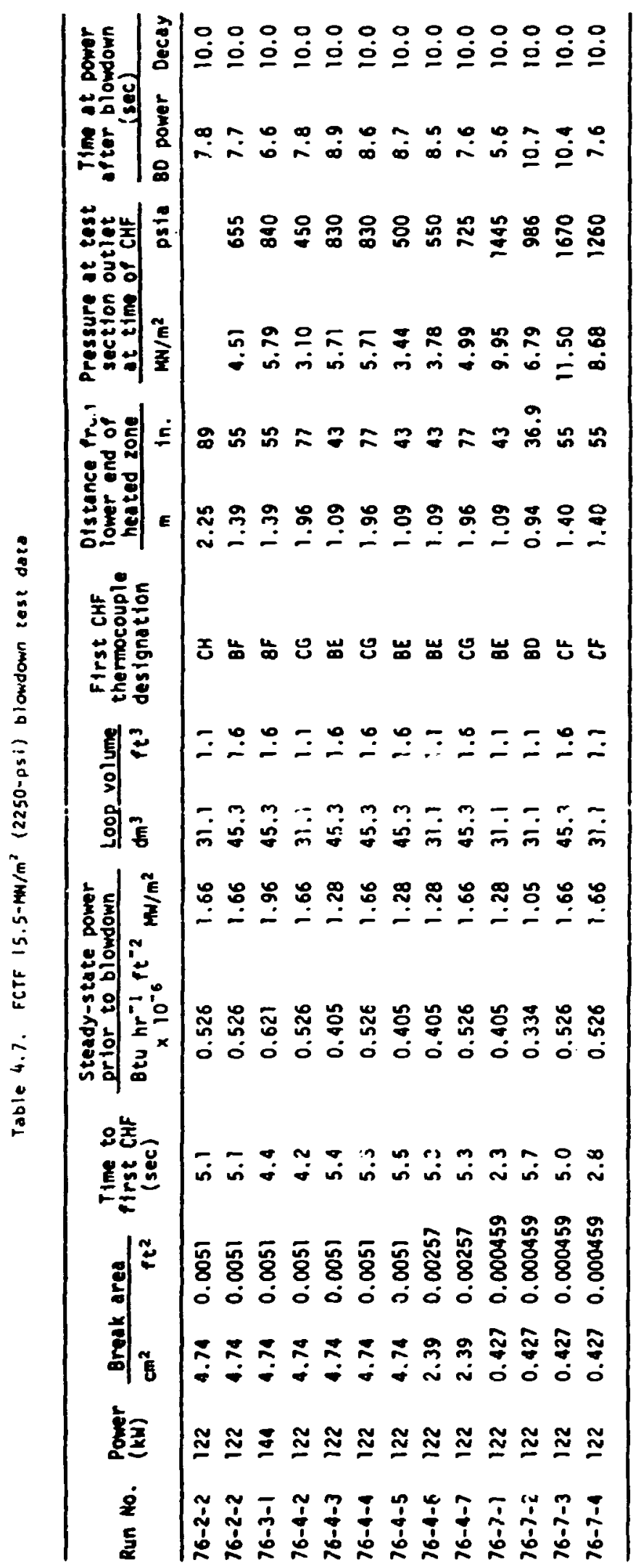




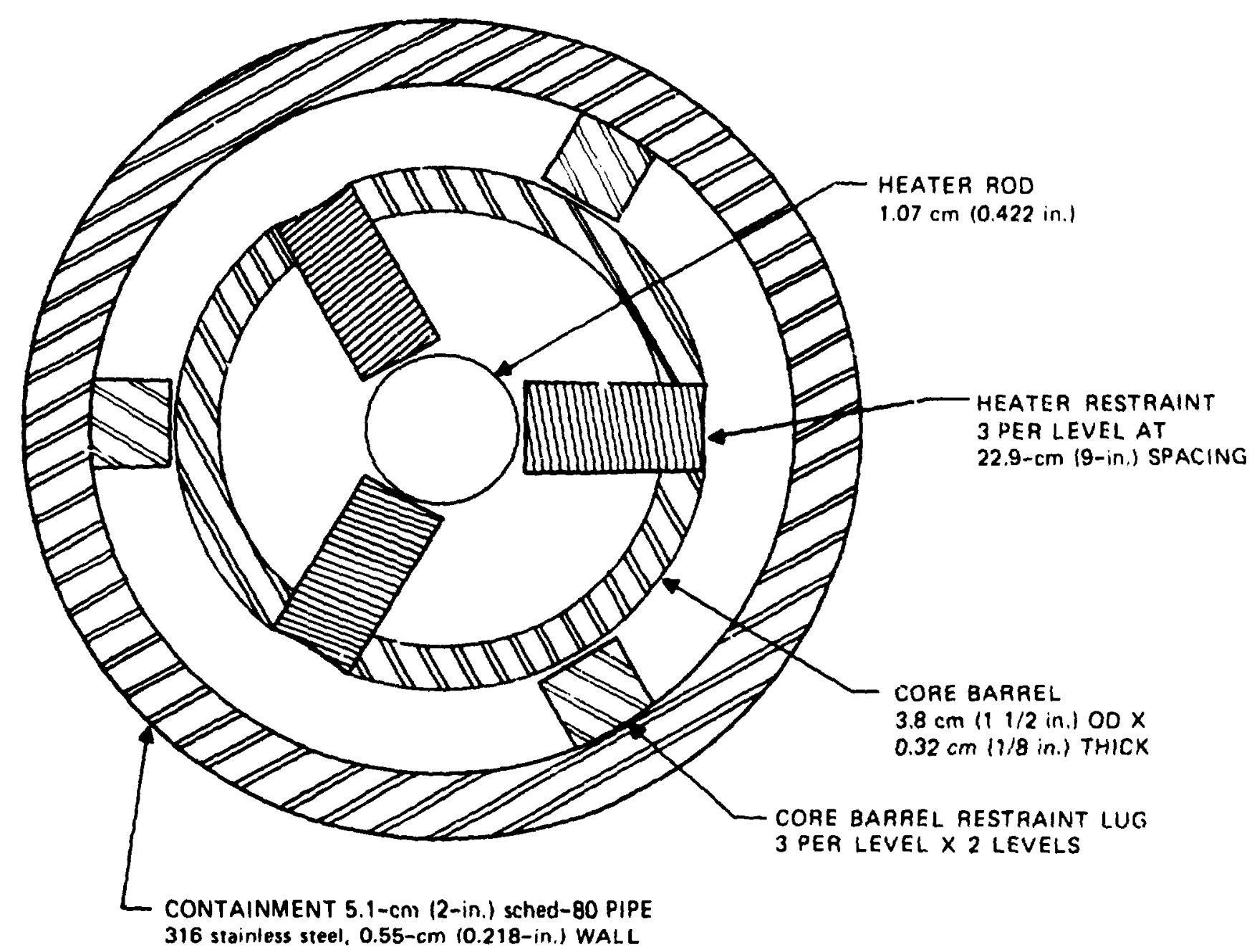

Fig. 4.10. Cross-sectional view of old FCTF test section. 

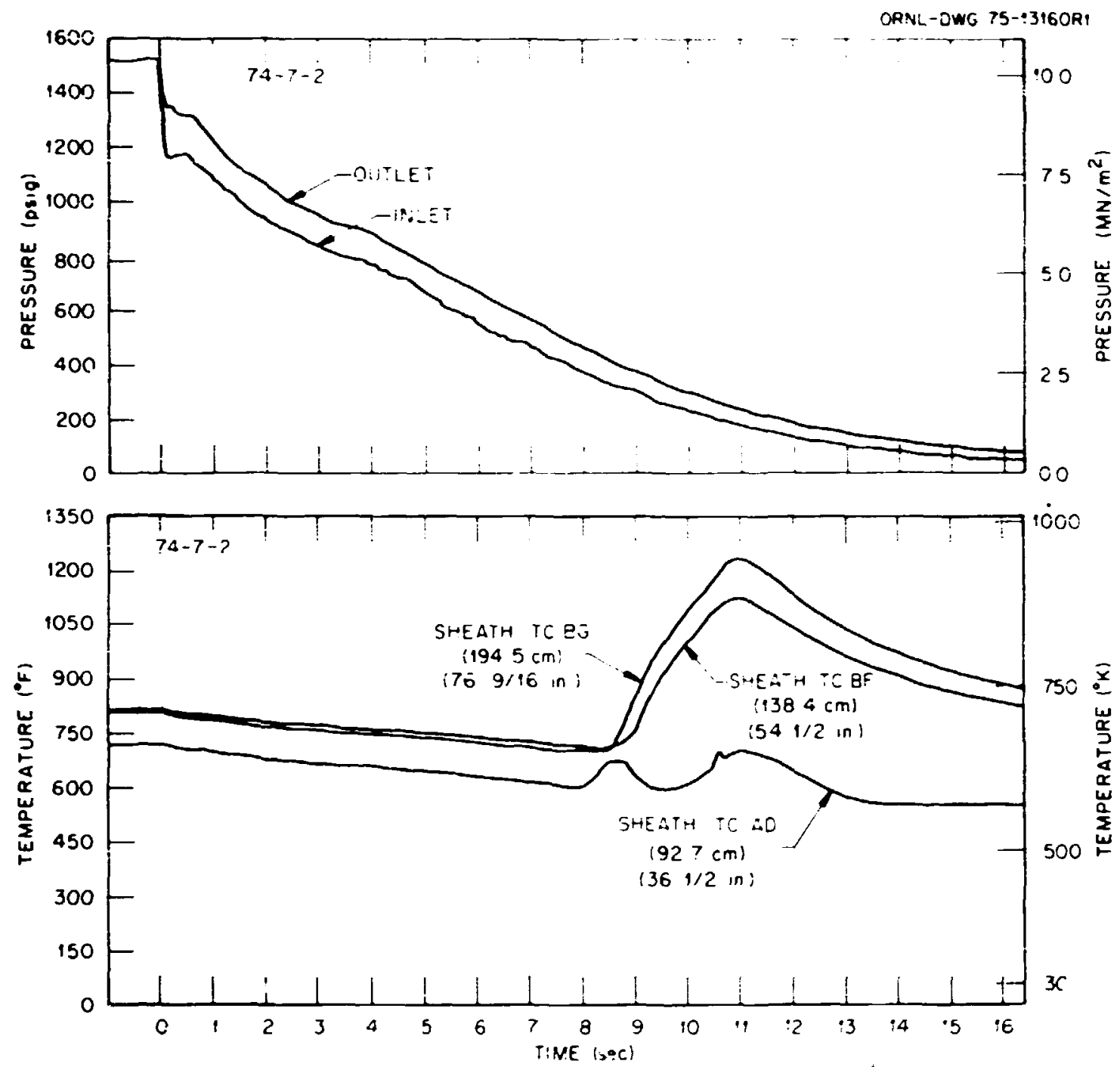

Fig. 4.11. Depressurization curves and sheath thermocouple response during blowdown in FCTF ? rod power - $144 \mathrm{~kW}$, break area $4.74 \mathrm{~cm}^{2}(0.005 \mathrm{I}$ $\left.\mathrm{ft}^{2}\right)$, system volume $\left.=0.071 \mathrm{~m}^{3}\left(2.5 \mathrm{ft}^{3}\right)\right]$.

observed behavior during most of the blowdown testirg done in the FCTF using the old test section.

Data obtained with the new test section will not be presented in this report. Representative times to $\mathrm{CHF}$ have been 0.4 to $1.0 \mathrm{sec}$ as compared to 4 to $8 \mathrm{sec}$ with the old test section. The shorter times to CHF are probably due to the smaller equivalent diameter of the new test section. 


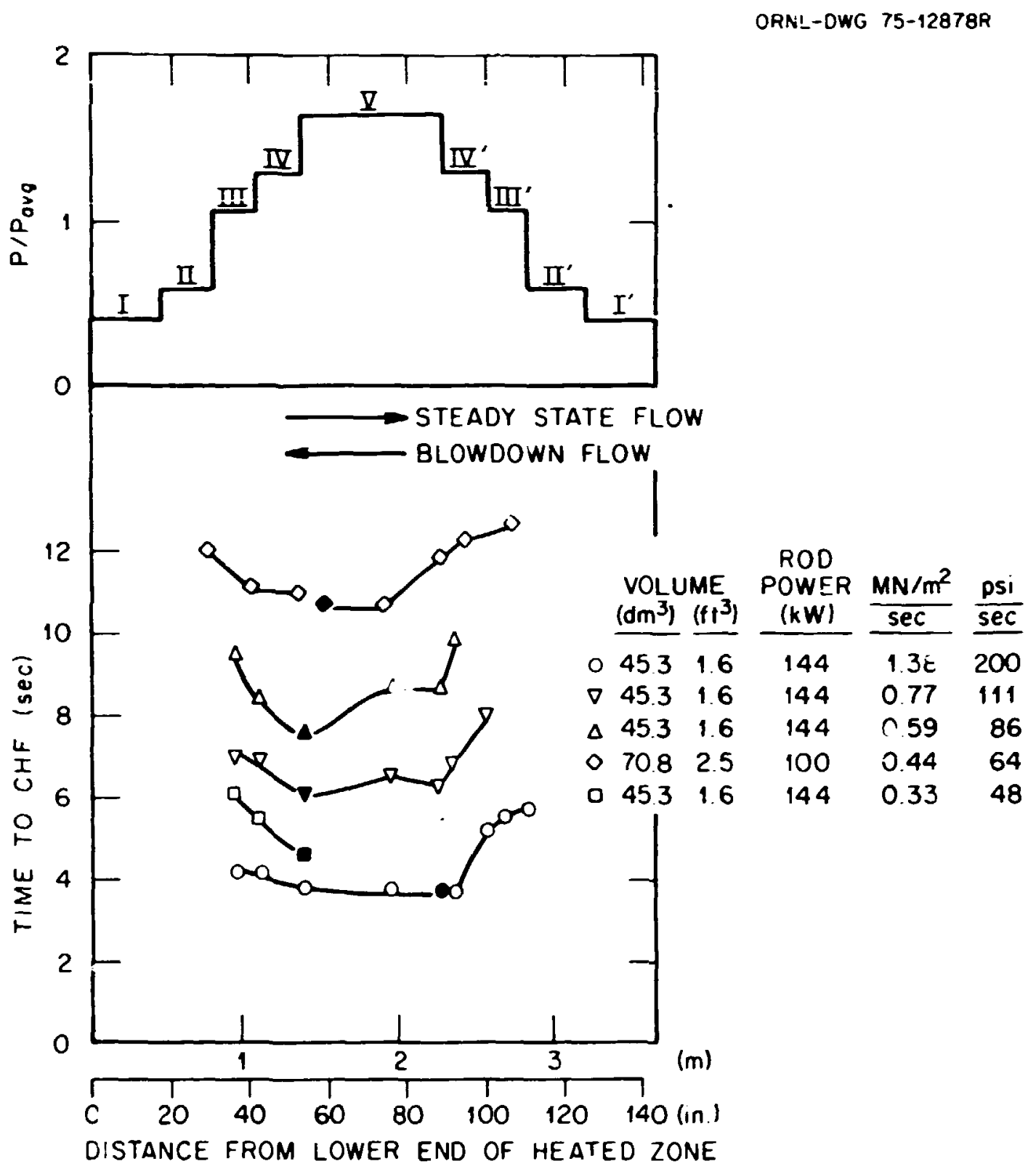
FCTF.

Fig. 4.12. Propagation of CHF along heater rod during blowdowns in

The data in Tables 4.6 and 4.7 show that the location of first CHF is usually in levels $D, E, F$, and G. Under blowdown conditions, these thermocouple levels are either in the highest heat flux zone or downstream of it. The repeatability of the location and times to $\mathrm{CHF}$ were excellent. 


\subsubsection{Time constants of sheath thermocouples}

A variety of tests have been conducted to determine the time constants of the sheath thermocouples in BDHT fuel pin simulators: heatups and cooldowns of a heater in air, quench tests in which a heater is heated to $1089 \mathrm{~K}\left(1500^{\circ} \mathrm{F}\right)$ in air and then dropped into water, and forced convection cooldow tests at different flow rates in the FCTF. Typical results for heatup and cooldown tests in air are shown in Fig. 4.13; an external thermocouple was tack-kelded to the heater surface near a sheath thermocouple. The sheath thermocouple reading followed the external thermocouple reading very closely throughout the heating and cooling transients. Another experiment entailed operating heater w150-74 in the FCTF at full power and then tripping the power while monitoring the thermocouple outputs. Similarly, the heater was operated at $1.2 \mathrm{~kW}$ in the FCTF without water and then the power was tripped again. Typical results are shown

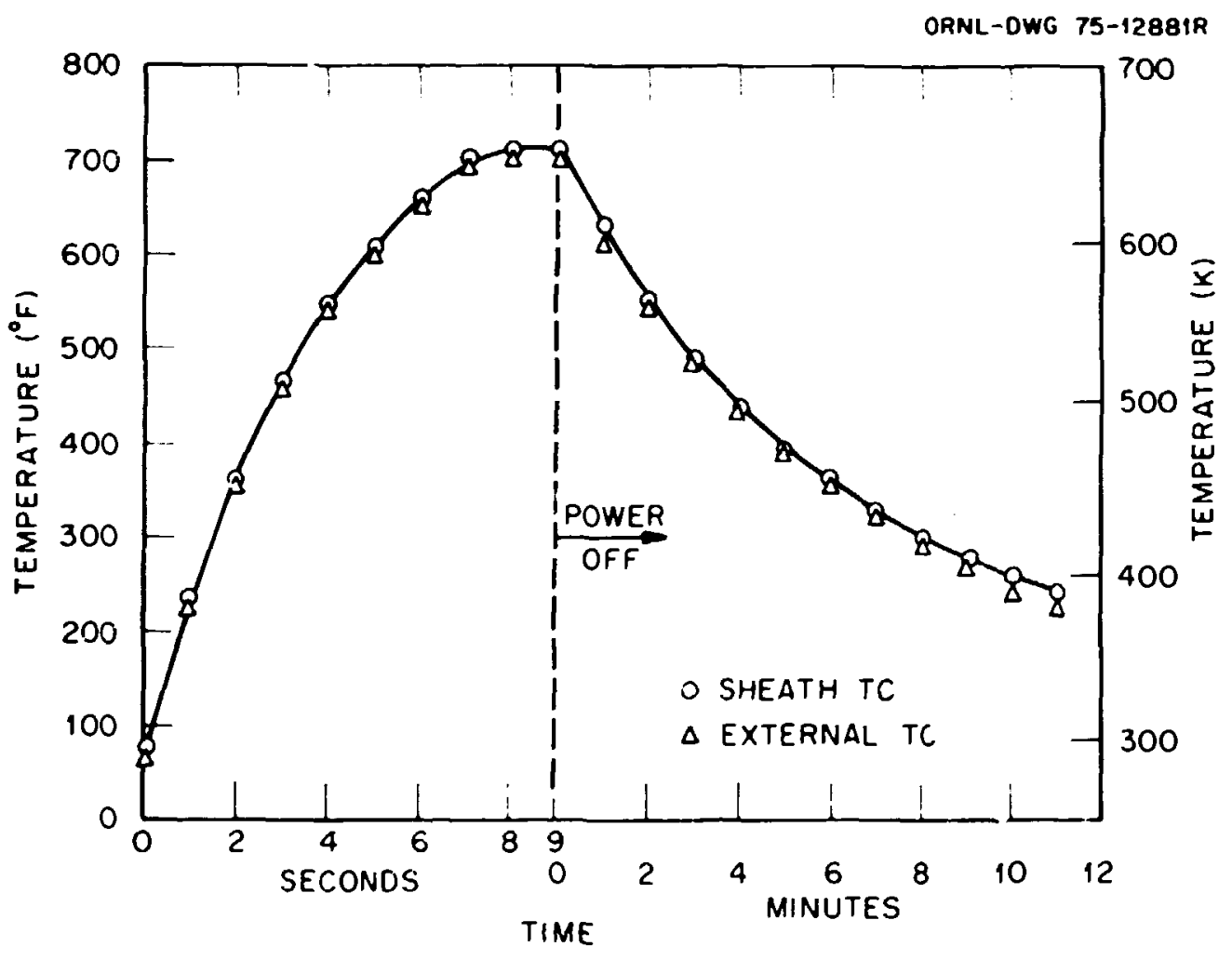

Fig. 4.13. Response of heater rod sheath thermocouple for a step change in rod power (air cooling). 
in Fig. 4.14 for these two widely different heat transfer conditions; the derived thermal time constants were $2.1 \mathrm{sec}$ for the forced-convection case in water and $330 \mathrm{sec}$ for natural convection in air.

Quench tests were also performed with heater W150-74. A 0.25-mm-diam (0.10-in.) Chromel/Alumel thermocouple was spot-welded to the outside of the heater at the same axial location as sheath thermocouple $B G$, and the heater was energized in a horizontal position to $1.2 \mathrm{kw}$ (heater sheath

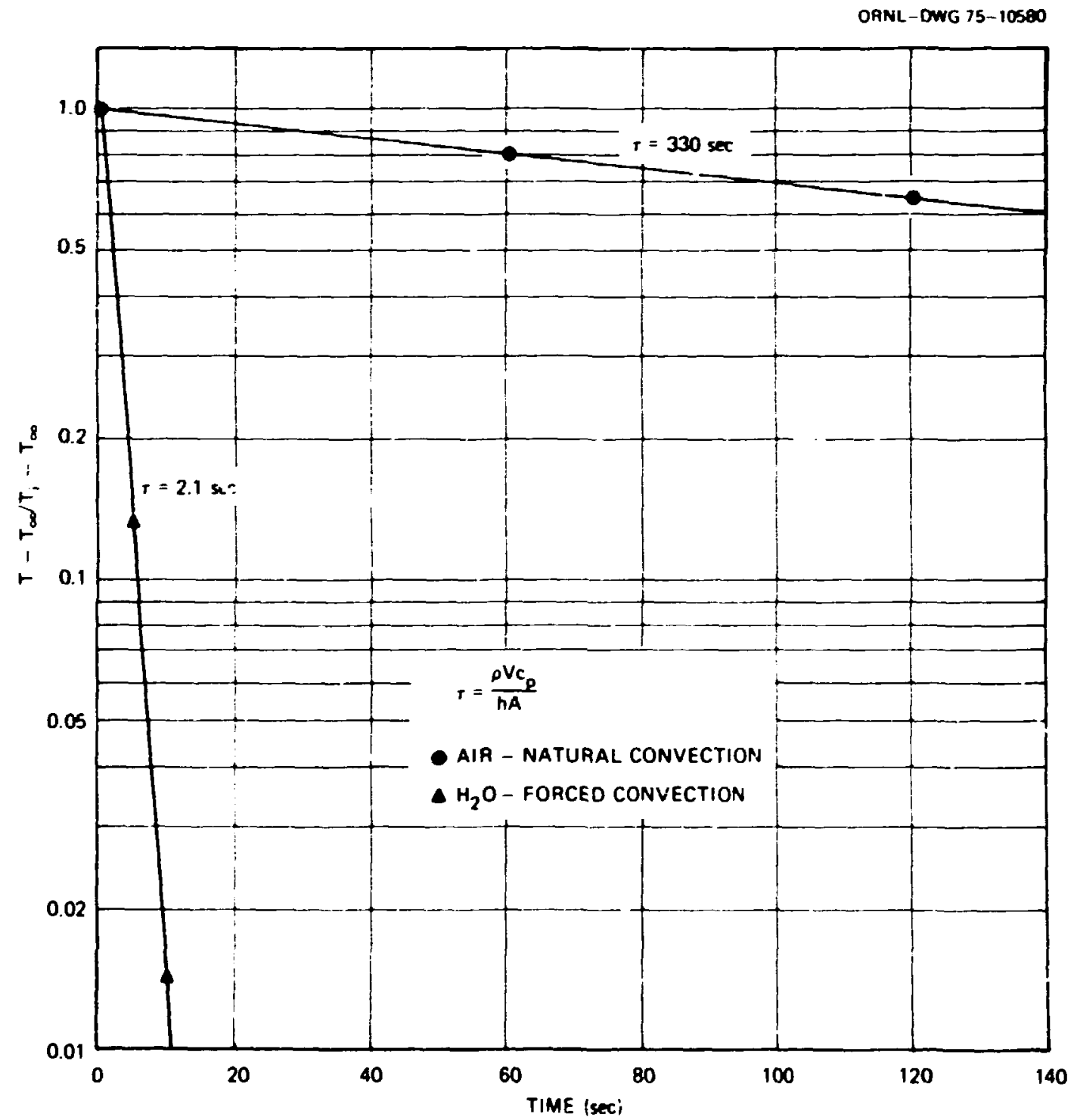

Fig. 4.14. Time response of sheath thermocouples in heater rod for air and water cooling. 
temperature approximately $1500^{\circ} \mathrm{F}$ ) until the central zone of the heater glowed cherry red. The power was then tripped and the entire heater lowered quickly into a $297 \mathrm{~K}\left(75^{\circ} \mathrm{F}\right)$ water bath. The outpus of the thermocouples respunded as shown in Fig. 4.15, and the time constants of the sheath thermocouples were approximately $1 \mathrm{sec}$.

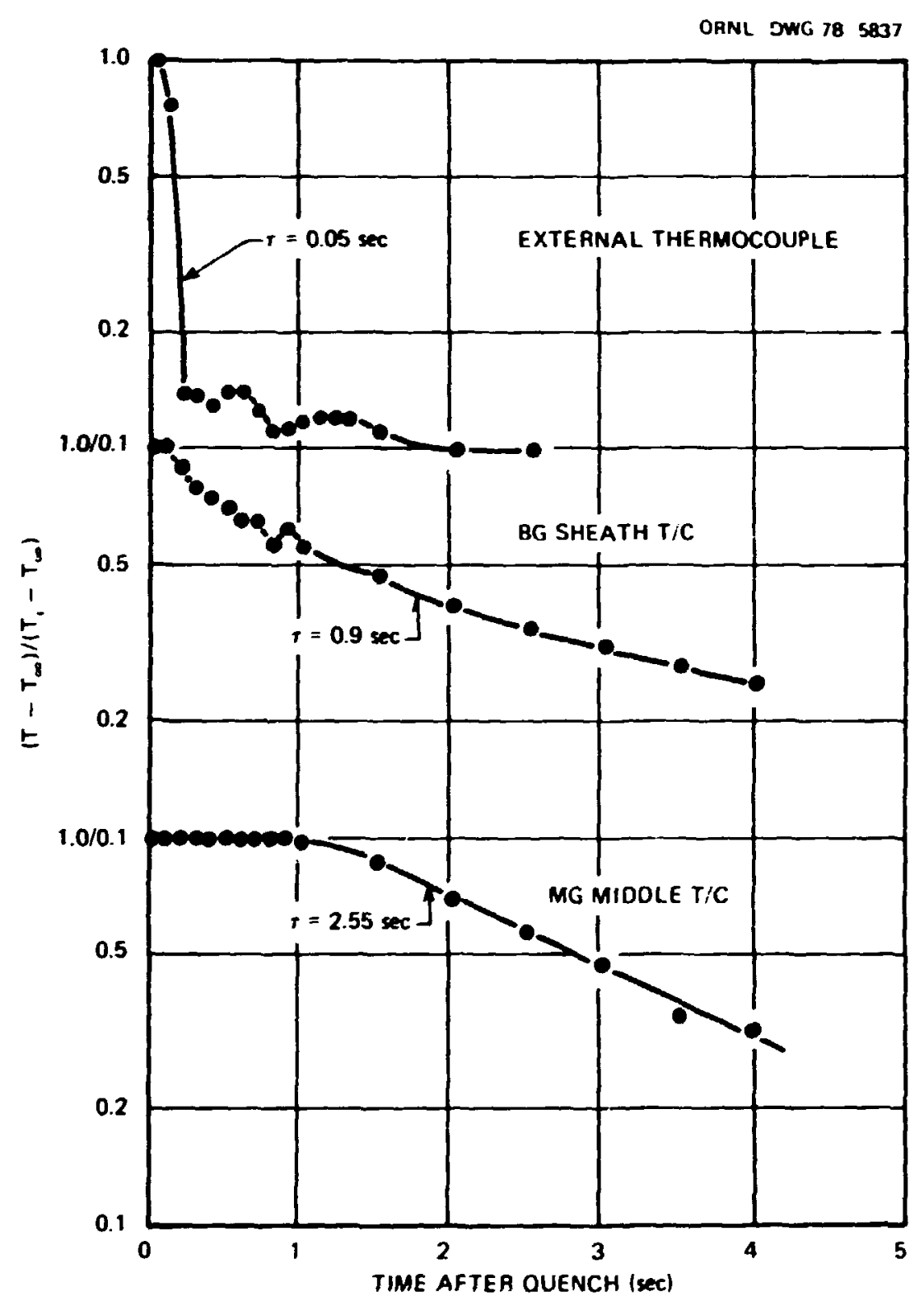

Fig. 4.15. Time response of sheath thermocouples in heater rod during a quench test. 
First-order theory suggests that the time constant of a thermocouple in-situ assembly will be given by

$$
\tau=\rho \mathrm{VC}_{\mathrm{p}} / \mathrm{hA}
$$

where

$$
\begin{aligned}
& \tau=\text { in-situ time constant of thermocouple, } \\
& \rho=\text { mean density, } \\
& \mathbf{V}=\text { volume of thermocouple assembly, } \\
& \tau_{\mathbf{p}}=\text { mean specific heat, } \\
& \mathrm{h}=\text { surface heat transfer coefficient, } \\
& A=\text { heat transfer area. }
\end{aligned}
$$

A plot of measured values of $\tau$ vs estimated values of the heat transfer coefficient indicates that the time constant is an inverse function of heat transfer coefficient (Fig. 4.16).

\subsection{Electrical Performance}

\subsubsection{Heater element resistance}

The electrical resistance of the heating element of each fuel pin simulator was measured before testing in the FCTF, while the room-temperature resistance was measured after each blowdown test. From test to test, measured values of resistance agree very well as shown in Table 4.8 for bundle 2 prototype $5 \mathrm{~N}-13$. The range of the measured resistances for six tests is 0.407 to $0.411 \Omega$, with a total variation of only $0.004 \Omega$, or about $1 \%$ of the measured value. Uncertainties in the measurement are also about $1 \%$; therefore, no significant run-to-run variation in resistance was observed for this heater. The other heaters tested also had nearly constant run-to-run values of heating-element resistance.

The resistances of the heating element during a blowdown test seem to be nearly constant. In Table 4.9, the calculated values $(R=E / I)$ of heater resistance are nearly the same for the bundle 1 production simulator W150-74 throughout the first approach to full power. The loop temperature varied from 422 to $561 \mathrm{~K}$ ( 300 to $550^{\circ} \mathrm{F}$ ) and the power varied from 10 to $144 \mathrm{~kW}$. These results are typical of all the simulators tested. 


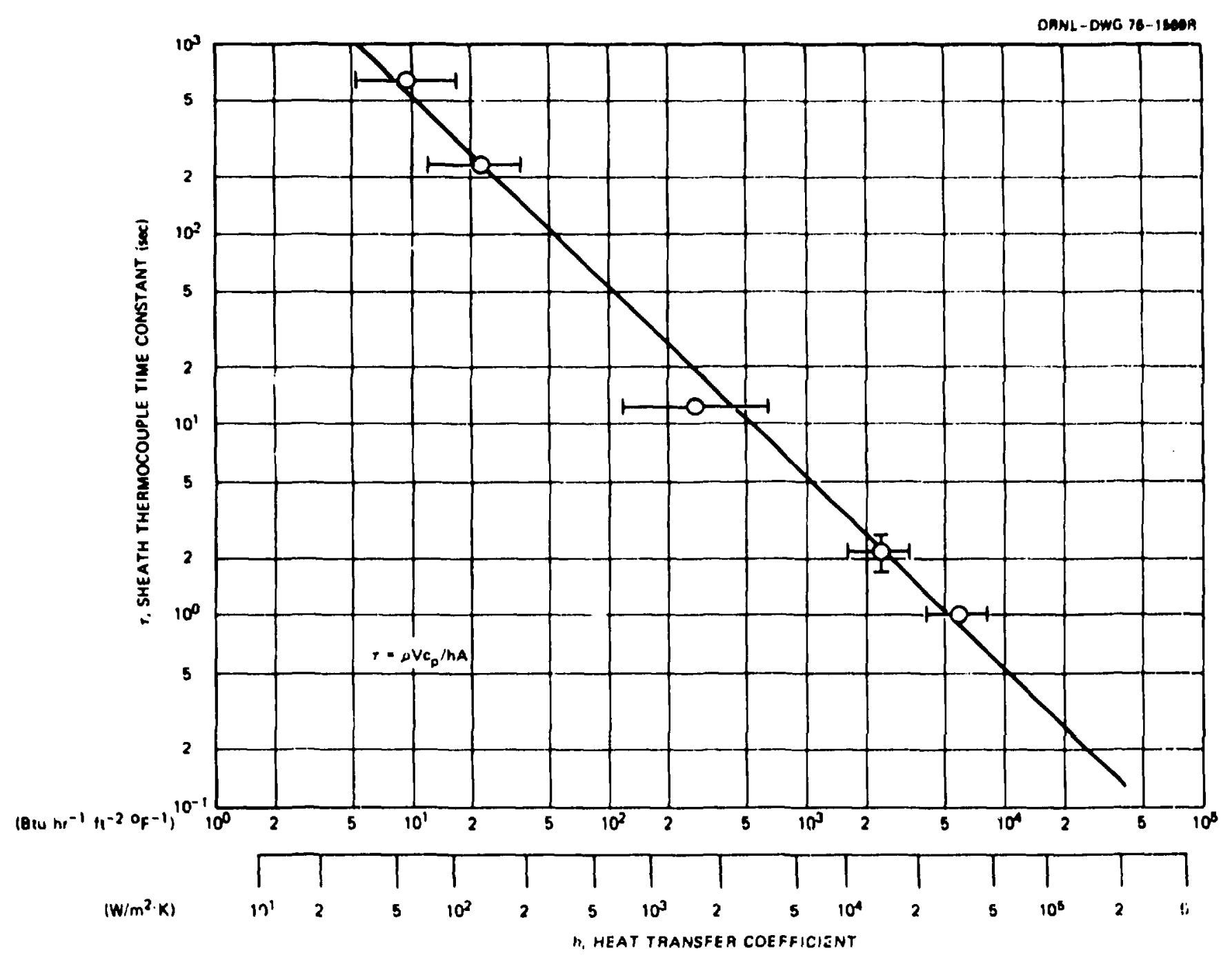

Fig. 4.16. Dependence of sheath thermocouple time constarit on surface heat transfer coefficlent. 
Table 4.8. Simulator $5 \mathbf{x - 1 3}$ heating element resistance

\begin{tabular}{cc}
\hline Run No. & $\begin{array}{c}\text { Resistance } \\
(\Omega)\end{array}$ \\
\hline & \\
0 & 0.411 \\
1 & 0.409 \\
2 & 0.407 \\
3 & 0.409 \\
4 & 0.409 \\
5 & 0.409 \\
6 & 0.409 \\
\hline
\end{tabular}

Table 4.9. Calculated heater element resistance values for bundle 1 fuel pin simulator during first approach to full power

\begin{tabular}{|c|c|c|c|c|}
\hline $\begin{array}{l}\text { Power } \\
(\mathrm{kW})\end{array}$ & $\begin{array}{l}\text { Inlet temp. } \\
{\left[\mathrm{K}\left({ }^{\circ} \mathrm{F}\right)\right]}\end{array}$ & $\begin{array}{l}\text { Voltage } \\
\text { (V) }\end{array}$ & $\begin{array}{l}\text { Current } \\
\text { (A) }\end{array}$ & $\begin{array}{c}\text { Heater element calculared } \\
\text { resistance } R=E / I \\
(\Omega)\end{array}$ \\
\hline 10 & $422(300)$ & 66.7 & 120 & 0.556 \\
\hline 20 & $422(300)$ & 92.3 & 228 & 0.405 \\
\hline 30 & $422(300)$ & 110.8 & 276 & 0.401 \\
\hline 40 & $422(300)$ & 127.9 & 320 & 0.400 \\
\hline 50 & $422(300)$ & 143.4 & 356 & 0.403 \\
\hline 60 & $422(300)$ & 156.4 & 388 & 0.403 \\
\hline 80 & $422(300)$ & 181.7 & 448 & 0.406 \\
\hline 100 & $477(400)$ & 202.3 & 496 & 0.408 \\
\hline 120 & $533(500)$ & 221.3 & 548 & 0.404 \\
\hline 144 & $561(550)$ & 242.0 & 596 & 0.406 \\
\hline
\end{tabular}

\subsubsection{Insulation resistance of $\mathrm{MgO}$ and $\mathrm{BH}$}

The insulation resistances of the $\mathrm{BN}$ and $\mathrm{MgO}$ materials are measured at the vendor factory before the bottom ground plug is welded onto the heater (thereby grounding the heating element to the sheath of the simulator). Specifications written for the procurement of bundle 2 simulators call for a room-temperature insulation resistance of $10,000 \mathrm{~m} \Omega$-ft as measured using a $500-\mathrm{V}$ dc potential. 
Operationally, the quality of the MgO insulation resistance is determined by the measurement of the leakage current from the heating element to the center thermocouple sheaths. This measurement is performed periodically during powered operation of a simulator. Typically, the leakage current at full power is about $0.5 \mathrm{~mA}$; however, during a first approach to power, leakage currents above 13 wa have been measured. These initially high values oi leakage current are probably due to absorbed moisture in a simulator. As the heater becomes hot, the leakage current decreases to 0.5 $\mathrm{mA}$ or below, indicating that the moisture is being driven from the heater.

During a CHF condition, the temperatures inside a fuel pin simulator are sometimes quite high. Since the $\mathrm{MgO}$ insulation resistance increases dramatically with temperature, the leakage current increases to high levels. The measurement of this transient in the leakage current has not been performed; plans to perform the measurement are being made.

At room-temperature and zero-power conditions, a $500-\mathrm{V}$ test of $\mathrm{MgO}$ insulation resistance is made before each blowdown test. The insulation resistance of the $\mathrm{MgO}$ in heater $\mathrm{W} 150-74$ was measured to be $140 \times 10^{6} \mathrm{~S}$ before the first blowdown test in the FCTF. After 14 blowdowns, the measured value was still greater than $100 \times 10^{6} \Omega$. This high resistance indicates that no appreciable moisture was picked up by the MgO during the testing period. The longest pericd between tests was 25 days.

\subsection{Mechanical Performance !}

\subsubsection{Retention of designed geometry}

Since the BDHT fuel pin simulators used in the THTF will be in close proximity, the geometry of each simulator must remain neafly constant throughout the THTF program. None of the simulators tested in the FCTF exhfbited significant bulges or bowing as long as the maximum temperature was below $1089 \mathrm{~K}\left(1500^{\circ} \mathrm{F}\right)$. Bundle 1 production heater $6150-74$, for example, operated for 20 blowiowns and $35 \mathrm{hr}$ at full power with no significant observable mechanical deterioration. Micrometer measurements of the heater diameter, shown in Table 4.10, were nearly the same before and after the testing. 
Table 4.10. Micrometer measurements of W150-74 ieater diameter

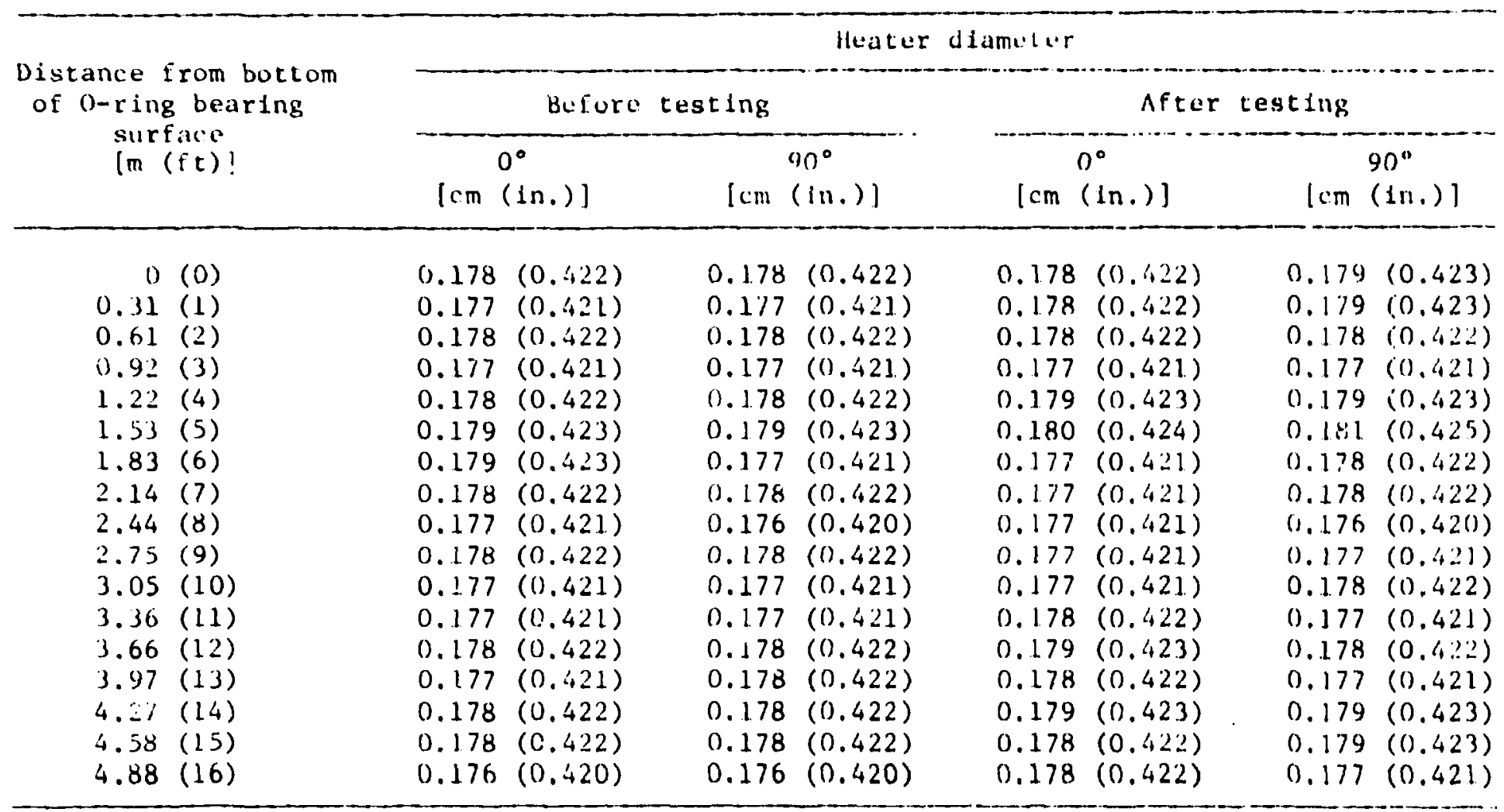




\subsubsection{Integrity of heater surface}

Most heater surfaces undergo some discoloration. The highest heat flux zones, which usually reach the highest temperature levels during CHF, hive the darkest surfaces. A dark powdery film covers the surface of heaters in some areas. The effect of the film on the heat transfer properties of a simulator are assumed negligible.

Dye penetrant tests of the surface of each fuel pin simulator are performed at the vendor factory and repeated after blowdown testing. 0nly in the cases of preprototype heaters $W 150-1$ and $W 150-3$ have the penetrant tests revealed cracks through the outer surface. The surface of preprototype simulator W150-1 was abraded by centering screws in the old FCTF test section, resulting in ultimate failure. The cause of the failure of w150-3 has not been determined. This heater, however, was rejected because of unacceptable infrared scans before blowdown testing.

\subsubsection{Integrity of power connections}

The suitability of the design of power connections to a fuel pin simulator is tested under operating conditions in the $\overrightarrow{r C T F}$ which are almost identical to those of the THTF. The upper power connector is brazed to the copper lead-in of a fuel pin simulator (Fig. 2.1). Tests of this design showed that temperatures of $716 \mathrm{~K}\left(830^{\circ} \mathrm{F}\right)$ were at tained at full-power operating conditions on heater w150-5 (bundle 1 prototype). Although the braze joint held at these temperatures, air cociling of this section of the heater was found to be necessary to prevent deterioration of the heater moisture seal. The THTF design provides $0.24 \mathrm{~m}^{3} / \mathrm{sec}(500$ cfm) of air cooling to these seals.

A nickel plate with machine-tapered holes provides lower electrical contact with the tapered bottoms of the heaters in the THTF. This type of arrangement has been utilized with a nickel electrode in the FCTF, shown in Fig. 3.3, for the testing of all hraters except the three preprototypical units (the bottom electrode design was not available). The nickel electrode contains a tapered hole machined to the same specifications as those in the nickel plate of the THTF. No assembly, disassembly, 
or operational difficulties with this design have occurred during the testing program.

\subsubsection{Adequacy of heater pressure seals}

The epper pressure seals of the FCTF and THTF facilities are provided by elastomer 0-ring seals. These 0-rings are compressed between heater bearing surfaces and grooves machined into the seal plates of the loops. This design allows heaters to expand and contract axially (thermal expansion) through the 0-rings during ths experiment. The $0-$ ring seal assembly of the FCTF is shown in Fig. 3.4 .

Viton 0-rings were first used during the sequence of tests on w150-74. The bottom 0-ring leaked during testing, but the upper two maintained the proper seal. Examination of the 0-rings after the heater was removed showed that the bottom $r$ ing was permanently flattened where it contacted the heater. A cossiderable degree of hardening of this 0-ring was noticed. The other 0-rings were more pliable and showed less flattening than the bottom ring. In fact, the ranking of the rings with respect to overall condition was top, middle, bottom. This gradation of deterforation had bean observed previously in tests using ethylene propylene 0-rings. The lower $0-r$ ings are exposed to higher temperature and apparently undergo more deterioration. The temperatures experienced by the lowest $0-r i n g s$ in the THTF seal assemblies will probably be lower than those encountered by w150-74 0-rings. Water at $450 \mathrm{~K}\left(\sim 350^{\circ} \mathrm{F}\right)$ will be introduced into the top of the THTF test section just below the lowest 0-rings and will probably provide them with a less hostile atmosphere.

\subsubsection{Temperature limits for mechanical integrity}

The maximum allowable temperature for a Watlow BDHT fuel pin simulator seems to be limited oniy by the melting points of the internal components. This preliminary hypothesis is based on the results of tests Involving the two bundle 2 prototype heaters. During these tests, the upper cemperature level trips on the heater power were set at progressively higher temperatures. After a critical heat flux condition occurred during a blowdown, full power was maintained until one of the heater thermocouple outputs increased beyond the temperature trip set point. In the critical 
heat flux regime, some of the heater temperatures increased at rates of up to $167 \mathrm{~K} / \mathrm{sec}\left(300^{\circ} \mathrm{F} / \mathrm{sec}\right)$.

As the heater temperatures rise, the insulation resistances of the MgO and the BN ceramic fillers decrease rapidly. Since overall insulation resistance decreases during this iransient heatup, the leakage current from the heating element to the center thermocouple sheaths increases. If the insulation resistance continues to decrease, an arc may develop and cause melting of heater components. In the first bundle 2 prototype, the entire cross section of the heater melted in one axial location after a series of tests in which the upper temperature level trips were progressively increased.

Data taken during the testing of the bundle 2 prototypes indicate that excessive leakage currents ( $20.5 \mathrm{~A}$ ) occurred after the central heater temperatures reached $1533 \mathrm{~K}\left(2300^{\circ} \mathrm{F}\right)$. The melting point of the cupronickel alloy is approximately 1450 to $1520 \mathrm{~K}\left(2150\right.$ to $\left.2280^{\circ} \mathrm{F}\right)$, while the Inconel and stainless steel components of the heater melt at temperatures of $1640 \mathrm{~K}\left(2500^{\circ} \mathrm{F}\right)$. Both heaters exhibited no problems until these temperatures $>1533 \mathrm{~K}$ were approached during the CHF transient. As shown in Fig. 4.17, these problem situations were indicated by sudden increases in the slopes of the thermocouple time traces. Heasurements of $\mathrm{MgO}$ insulision resistance showed a short circuit between the heating element and the center thermocouples after this phenomenon was observed in each heater.

During a portion of a CHF transient, the heating element temperature may be higher than the tamperatures at the center thermocouples. The heating element could then reach its melting point some time before the center thermocouples indicate that temperature. The milten areas of the heating element could become local hot spots where the temperature would rise drastically. The $\mathrm{MgO}$ and $\mathrm{BN}$ ceramics would become very hot in the surrounding areas, with a resultant breakdown in insulation resistance.

The temperature trip point for the data shown in Fig. 4.17 was 1533 $K\left(2300^{\circ} \mathrm{F}\right)$. In the previous experiment, a temperature trip occurred at $1477 \mathrm{~K}\left(2200^{\circ} \mathrm{F}\right)$ with no resultant electrical breakdown. 
ORNL-DWG 77-12529R

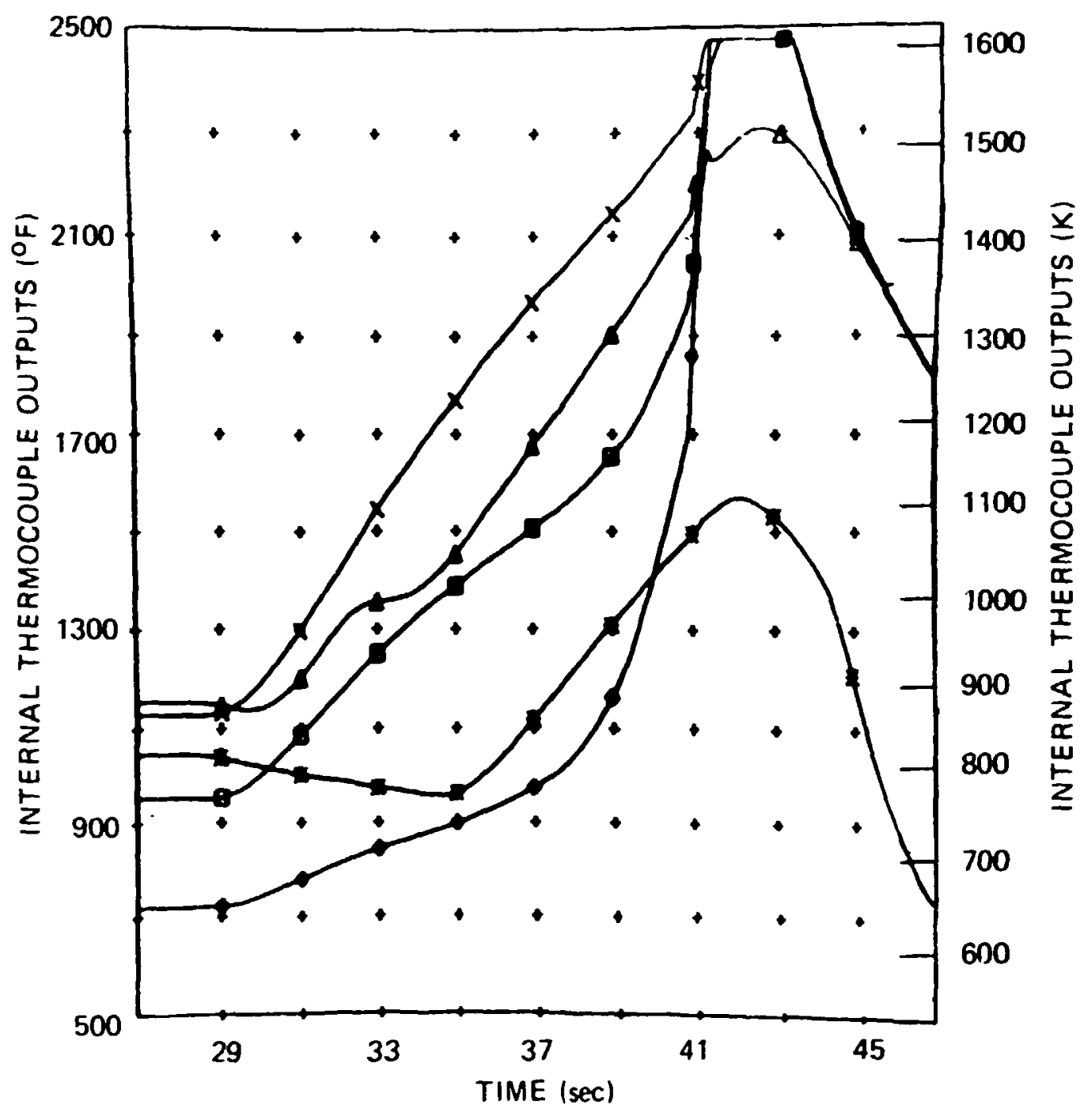

Fig. 4.17. Sheath thermocouple outputs of a fuel pin simulator during electrical breakdown of the simuiator resistance.

\subsubsection{Degradation of contact between swaged materials}

Assuming that a degradation of the contact pressure occurred between the swaged materials in the fuel pin simulator, then this hypothetical degradation of contact pressure would result in an increase in thermal resistance across the swaged area. An increase in the radial $\Delta T$ between two radial positions enclosing this area should be noticeable. The radial $\Delta T^{\prime} s$ frnm the center thermocouples to the sheath thermocouples at the same 
axial levels, however, have remained typically constant. This result suggests that no significant degradation of contact between the layers comprising the heating element, the Mgo-heating element interface, the BH heating element interface, or the $\mathrm{BN}$-inner sheath interface has occurred during the testing program.

The growth of a gap between the inner and outer sheaths was shown in Fig. 4.4. The effect of this increase in the associated thermal risistance across the gap was observed in increases in the sheath thermocouple outputs. Since the witer temperature was the same from run to run, increases in sheath thermocouple indications are equivalent to increases in $\Delta T$ from the inner sheath to the water. A possible cause for such an increase is the fouling of a heater surface. However, since the inspection of the surface of each heater after testing showed no discernible surface fouling, this possibility was discounted. 


\section{DISCUSSION}

The mechanical and electrical performances of the fuel pin simulators tested were satisfactory. The thermal performances of the simulators were sufficient for reliable time-to-CHF determinations and the location of the heat flux crisis; the simulators exhibited satisfactory power profiles; the time constants of the thermocouple; were reasonably short under conditions expected during blowdowns; and the thermometry was stable with time. The lezst satisfactory aspect of the typical simulator thermal response was the change in temperature profile caused by the generation of a gap between the inner and outer sheaths. This phenomenon makes the calculation of surface temperature and therefore of heat transfer coefficient difficult. As a result of the discovery of this phenomenon, a computer model and program was generated by ott ${ }^{4}$ of the BDHT program to alculate the growth of the gap and the temperature profile in that area and future bundles will be designed to eliminate dual sheaths. 


\section{REFERENCES}

1. Reactor Safety Research Program, NUREG-751058 (June 1975).

2. Project Description ORNL FWR Blowdown Heat Zransfer Separate-Effects Progran - Thermal Hydraulic jest Facility (THTF), ORNL/NUREG/TM-2 (February 1976).

3. Anticipated Trmsients Without Scran for Water-Cooled Power Reactors, WASH-1270 (September 1973).

4. L. J. Ott and R. A. Hedrick, OP.INC - A One-Dimensional Imslicit ADproach to the Inverse ieat Conduction Problem, ORVL/NUREG-23 (November 1977). 